University of Louisville

ThinkIR: The University of Louisville's Institutional Repository

Electronic Theses and Dissertations

$5-2006$

\title{
Motivational interviewing : does it increase alcohol and other drug addicted clients' retention in outpatient treatment?
}

David Allen Patterson

University of Louisville

Follow this and additional works at: https://ir.library.louisville.edu/etd

\section{Recommended Citation}

Patterson, David Allen, "Motivational interviewing : does it increase alcohol and other drug addicted clients' retention in outpatient treatment?" (2006). Electronic Theses and Dissertations. Paper 1100. https://doi.org/10.18297/etd/1100

This Doctoral Dissertation is brought to you for free and open access by ThinkIR: The University of Louisville's Institutional Repository. It has been accepted for inclusion in Electronic Theses and Dissertations by an authorized administrator of ThinkIR: The University of Louisville's Institutional Repository. This title appears here courtesy of the author, who has retained all other copyrights. For more information, please contact thinkir@louisville.edu. 


\title{
MOTIVATIONAL INTERVIEWING: DOES IT INCREASE ALCOHOL AND OTHER DRUG ADDICTED CLIENTS' RETENTION IN OUTPATIENT TREATMENT?
}

\author{
By \\ David Allen Patterson \\ B.S.W., Spalding University, 1996 \\ M.S.S.W., University of Louisville, 1997
}

A Dissertation Submitted to the Faculty of the Graduate School of the University of Louisville in Partial Fulfillment of the Requirements for the Degree of

Doctor of Philosophy

Kent School of Social Work

University of Louisville

Louisville, Kentucky

May, 2006 


\section{MOTIVATIONAL INTERVIEWING: DOES IT INCREASE ALCOHOL AND OTHER DRUG ADDICTED CLIENTS' RETENTION IN OUTPATIENT TREATMENT? \\ By \\ David Allen Patterson \\ B.S.W., Spalding University, 1996 \\ M.S.S.W., University of Louisville, 1997 \\ A Dissertation Approved on}

April 20, 2006

By the following Dissertation Committee:

\begin{tabular}{c}
\hline Ruth Huber, Ph.D., Chair \\
\hline Rick Cloud, Ph.D. \\
\hline Seana Golder, Ph.D. \\
\hline Riaan van Zyl, Ph.D. \\
\hline Carl Leukefeld, DSW
\end{tabular}




\section{DEDICATION}

This dissertation is dedicated to my wife Nicole Patterson and our children, Ambra, Conall, and Aidan. 


\section{ACKNOWLEDGMENTS}

Disregarding any particular order, along with the realization that I could not possibly acknowledge everyone responsible for this dissertation I owe a great debt to many people. I first want to thank all of those people seeking services within the Volunteers of America of Kentucky who were willing to participate in research with the hope of benefiting others. It was a privilege to be allowed into their lives. I am indebted to the Volunteers of America in Kentucky and the staff within those programs who also welcomed and offered their assistance.

I thank my chair, Dr. Ruth Huber, who graciously provided support and direction during my entire time in the Ph.D. program and who advocated for me on many occasions. My mentor and friend Dr. Rick Cloud, while balancing both professional and personal responsibilities, provided me with the help and insight that lead to my success. To my remaining committee members, Dr. Riaan Van Zyl, Dr. Carl Leukefeld, and Dr. Seana Golder (who by the way gave birth to her daughter, Vivian, days before my defense), I thank you for your inspiration and support.

Dr. Patrick McKiernan, as well as the entire clan of McKiernans, who took a chance on me many years ago and provided mentorship throughout my professional career, I thank you. Lastly, I have to acknowledge the love, support and dedication from my poor ole Mama. I love you Ma! 


\section{ABSTRACT \\ MOTIVATIONAL INTERVIEWING: DOES IT INCREASE ALCOHOL AND OTHER DRUG ADDICITED RETENTION IN TREATMENT}

David A. Patterson

April 20, 2006

This dissertation is a post-test only comparison group study. It tests the effects of additional Motivational Interviewing sessions during the first two weeks in an intensive outpatient clinic. The object is to learn whether these additional sessions will help to increase rates of treatment retention and completion with alcohol and other drug addicted individuals as well as those who are dually diagnosed with HIVIAIDS infection and addiction. It begins with the problems associated with alcohol and other drugs followed by problems related to HIVIAIDS and treatments for both illnesses. It uses Transtheoretical Stages of Change Model as a guide for intervention development. The latter part of the dissertation describes the method used to study this population and the results.

The dissertation is divided into five chapters. Chapter I discusses the problems associated with alcohol and other drug addiction and HIVIAIDS followed by treatments related to those illnesses. Chapter II begins with reviewing the literature linked to treatment retention. This chapter identifies the 
theoretical perspectives of treatment retention and completion followed by an intervention development using Motivational Interviewing sessions as a means to address treatment retention and completion.

While Chapters I and II are descriptive and theoretical in nature, Chapter III focuses on designing a study to test the effects of an intervention on retention and completion. It lays out the methodology of the study such as its purpose, design, instruments, sample and variables. Chapter IV discusses the results of the study and Chapter $V$ discusses the implications of the results. 
TABLE OF CONTENTS

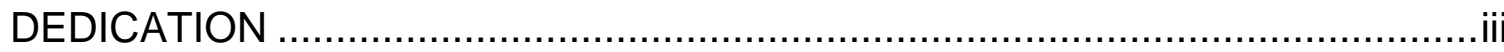

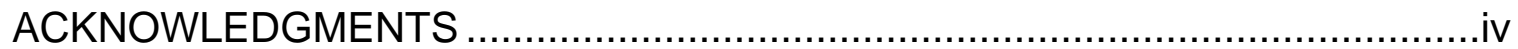

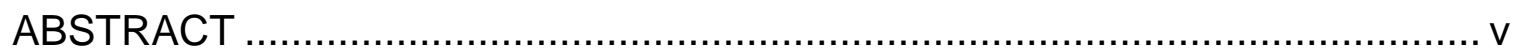

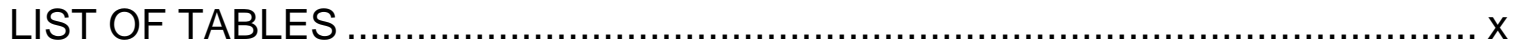

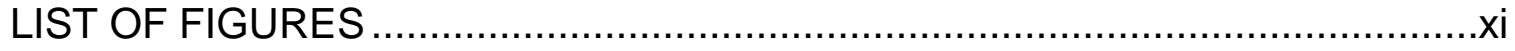

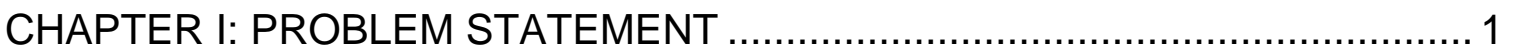

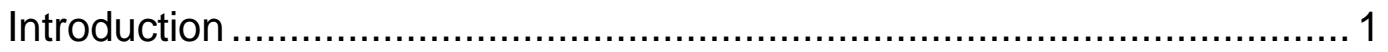

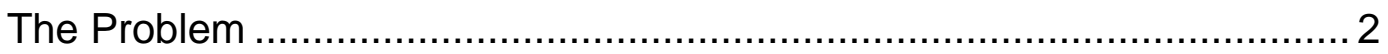

The Alcohol and Other Drug Problem ......................................... 3

The Costs: Financial and Human .......................................... 4

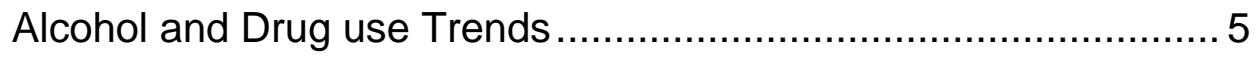

The Prevalence of HIVIAIDS .................................................. 7

HIVIAIDS Internationally ................................................ 7

HIVIAIDS in the United States ........................................ 8

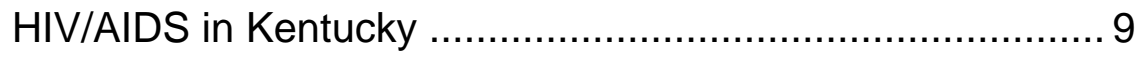

Demographic Trends ................................................... 10

The Importance of Studying Addiction \& HIVIAIDS Together....... 13

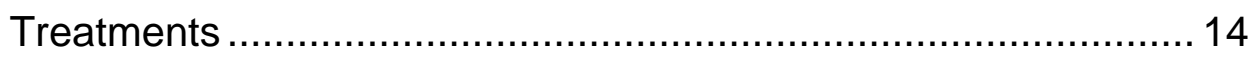

The History of Addiction Treatments ....................................... 15

Current Treatments ........................................................... 18

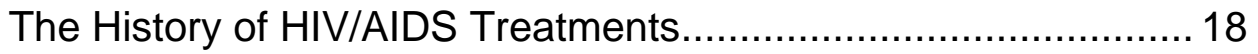

Combining Addiction and HIVIAIDS Treatment......................... 19 
CHAPTER II: REVIEW OF RELATED LITERATURE................................. 21

Treatment Retention and Completion Linked to Better Outcomes...........21

Rationale for Studying Retention......................................... 22

Retaining HIV-Infected Alcohol Dependent Individuals in Treatment.......22

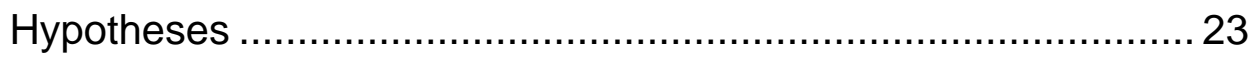

Theoretical Perspectives on Treatment Retention ................................ 23

Carl Rogers' Therapy and Therapeutic Relationship.................... 23

Transtheoretical Stages of Change Model ................................. 25

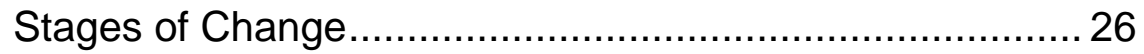

Prochaska's Therapy ..................................................... 29

The Therapeutic Relationship........................................ 30

Motivational Interviewing ...................................................... 31

Designing a Motivational Interviewing Intervention ............................... 32

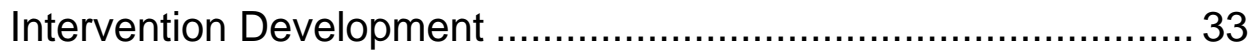

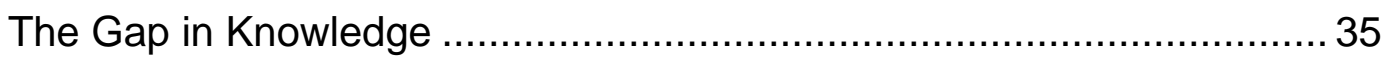

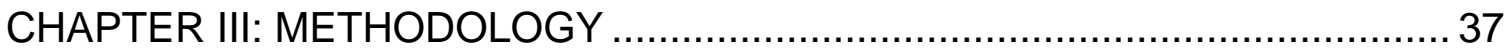

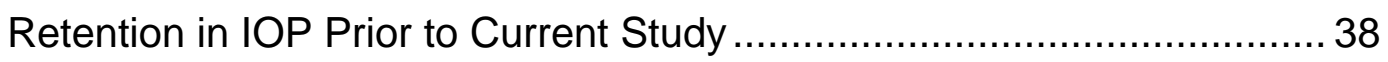

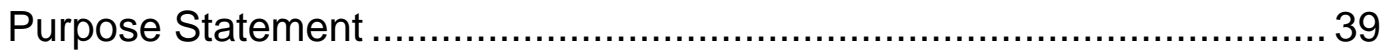

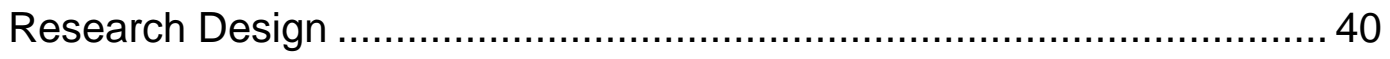

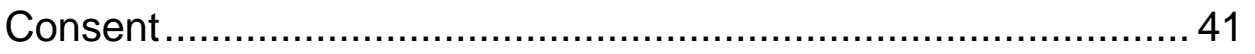

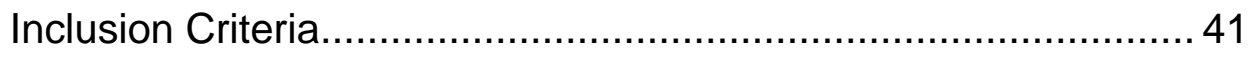

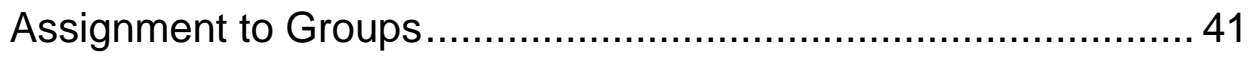

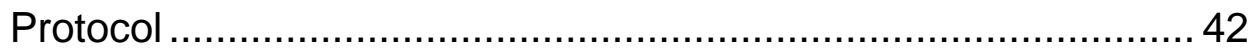




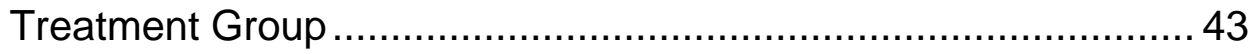

Operationalization of Variables ................................................... 44

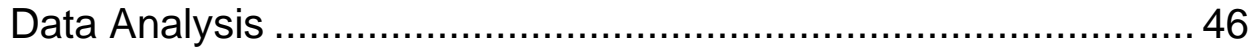

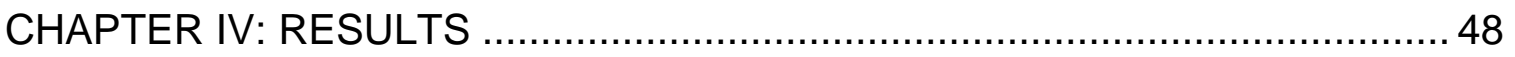

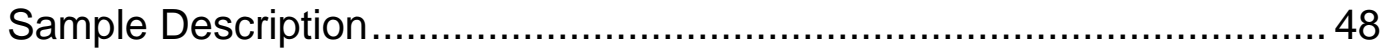

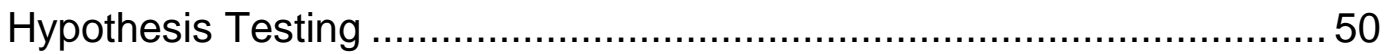

Retention and Completion by HIV Status............................................ 53

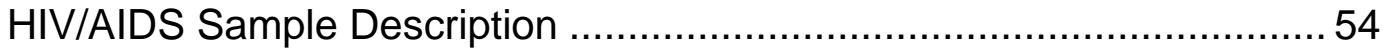

HIVIAIDS Status and Hypothesis 1 (Days in Treatment) ............... 55

HIVIAIDS Status and Hypothesis 2 (Treatment Completion) .........56

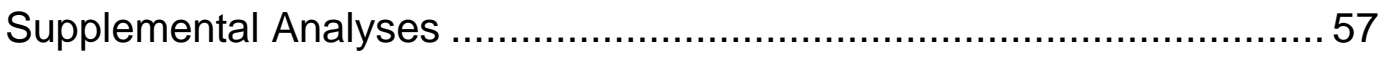

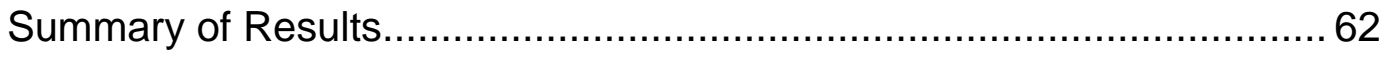

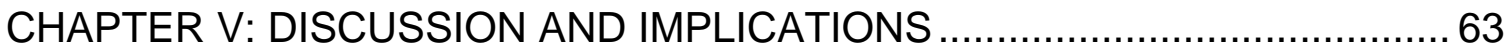

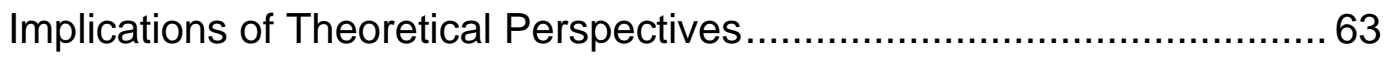

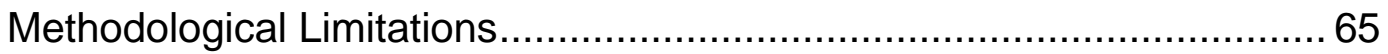

Research Inclusion and Exclusion Activities ........................................69

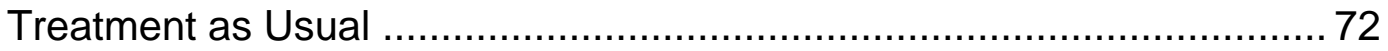

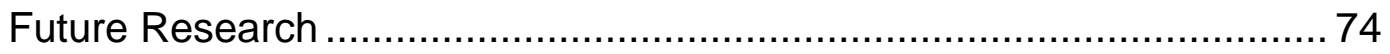

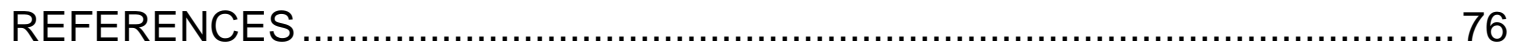

APPENDIX A: Description of Volunteers of America of KY Intensive ................. 89 Outpatient Alcohol/Drug Treatment

APPENDIX B: Description of Volunteers of America of KY Intensive ................. 91 Outpatient Alcohol/Drug Treatment

APPENDIX C: Motivational Interviewing: Protocol for Sessions on Retention... 95 CURRICULUM VITA .... 


\section{LIST OF TABLES}

TABLE

PAGE



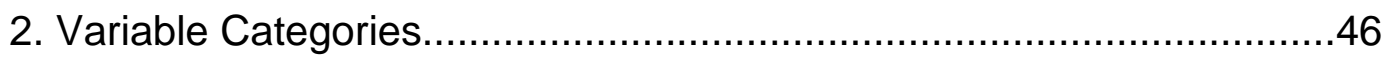

3. Baseline Characteristics of Respondents.........................................49

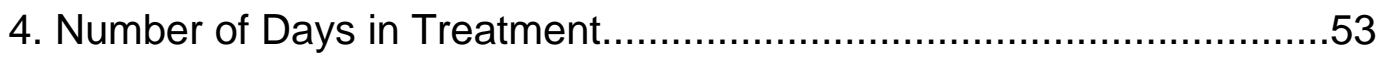

5. Dropout and Completion by Treatment and Comparison Group.......... 54

6. Baseline Characteristics of HIVIAIDS Positive Respondents................55

7. Treatment Completion by HIVIAIDS Status.......................................5

8. Number and Frequencies of MI Sessions.........................................58

9. Descriptive statistics of Total sample \& After Exclusion......................58

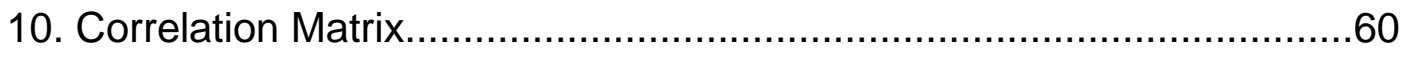

11. Unstandardized Regression Coefficients.......................................61

12. Relationship between HIVIAIDS \& Client Severity............................ 62 


\section{LIST OF FIGURES}

\section{FIGURE}

1. Number of AIDS Cases in Kentucky...............................................12

2. Histogram of Attendance for Total Sample.........................................50

3. Histogram of Attendance for Treatment Group........................................51

4. Histogram of Attendance for Comparison Group..................................52

5. Mean Number of Days in Treatment by Group and HIVIAIDS Status...... 56 


\section{CHAPTER I \\ PROBLEM STATEMENT}

Introduction

This dissertation was conducted within an intensive outpatient (IOP) clinic at the Volunteers of America (VOA) of Kentucky Inc. The IOP clinic has existing research infrastructure that is funded by a Substance Abuse and Mental Health Services Administration's (SAMHSA) Center for Substance Abuse Treatment (CSAT) grant. The grant enabled the Volunteers of America to establish an IOP

clinic specifically to treat individuals with alcohol and other drug addiction, which, according the SAMHSA also places them at a higher risk for HIV-infection.

The primary aim of the study is to test the effects of up to five Motivational Interviewing $(\mathrm{MI})$ sessions on treatment retention and completion delivered during the first two weeks of treatment. A post-test only design with comparison group - the treatment group (IOP + up to $5 \mathrm{MI}$ sessions) and comparison groups (IOP only) — was conducted. While the intention was to test the effects of a MI intervention with those subjects with alcohol and other drug (AOD) addiction seeking IOP services, there was also an attempt to enroll subjects who were dually diagnosed with AOD addiction and HIVIAIDS infected.

This dually diagnosed population (i.e., AOD addicted and HIVIAIDS infected) comprises a much smaller segment within the entire sample, but one 
that needs to be studied in order to address their needs during AOD treatment. Enrolling and analyzing these subjects will be guided by Rounsaville, Carroll, and Onken's (2001) Stage 1b pilot trial study. The Stage 1b allows for a limited number of subjects for pilot studies, 15 to 30 per cell along with establishing treatment efficacy and support for larger clinical trials.

\section{The Problem}

Alcohol has played a major role in people's lives throughout history. Alcoholic beverages in our society have been consumed with meals, served for medicinal or religious purposes, used to celebrate special occasions, and served as a social facilitator. While most individuals who drink alcohol do not develop problems with, or dependence on, alcohol, many social workers encounter high rates of alcohol problems among the clients they serve. Alcohol problems refer to any situation caused by drinking which directly harms the drinker, places the drinker at risk, or places others at risk. Alcohol use problems exist on a continuum of severity from occasional binge drinking to alcohol abuse or dependence.

This chapter opens with (a) this overview of the scope of the problems of addiction to AOD, and the HIVIAIDS pandemic (Human Immunodeficiency Virus [HIV] and Acquired Immunodeficiency Deficiency Syndrome [AIDS]). This is followed by (b) a discussion of the financial and human costs, (c) trends in AOD use, (d) the prevalence of HIVIAIDS, and (e) treatment for both addictions and HIVIAIDS. 


\section{The Alcohol and Other Drug Problem}

Alcohol abuse is described as continued drinking despite adverse effects on health, family, work or personal relationships, interpersonal problems, or alcohol-related legal problems (National Institute on Alcohol Abuse and Alcoholism [NIAAA], 2001). According to the NIAAA's web site (July, 2004) 100,000 Americans die of alcohol-related causes each year, making alcohol the third leading contributor to mortality related to lifestyle in the U.S. (tobacco is first, and diet and activity patterns are second). Nearly $53 \%$ of the adult population of the U.S. (98 million persons aged 18 or older) have family histories of alcoholism or problem drinking (July, 2004). Approximately 6.6 million children under age 18 live in households with at least one alcoholic parent.

According to SAMHSA's 2004 National Survey on Drug Use and Health, about half (50.3\%) of Americans aged 12 years or older reported that they consume alcohol. This converts into an estimated 121 million Americans drinking alcohol on a regular basis coded into three categories of use: Current, (at least 1 drink in the past month), Binge use, (5 or more drinks on the same occasion in the past month), and Heavy use (5 or more drinks on the same occasions on at least five different days in the past month). Almost 45\% (55 million) report binge drinking and just fewer than 14\% (17 million) are heavy drinkers. Almost 14 million U.S. adults meet medical criteria for the diagnosis of alcohol abuse or alcoholism, and over $30 \%$ of high school seniors engage in binge or heavy drinking. 


\section{The Costs: Financial and Human}

The estimated costs of alcohol disorders and their social consequences in 1998 were $\$ 185$ billion. Of this sum, direct treatment and health care costs accounted for $14 \%$, reduced worker productivity $47 \%$, and lost productivity due to premature deaths for $20 \%$ (July, 2004). Costs associated with alcohol-related traffic crashes - the fifth leading cause of death for Americans of all agesaccount for $9 \%$, as do costs associated with criminal activity. Almost $39 \%$ of these costs were spread across the U.S. population in the form of increased burden on government budgets.

Fetal alcohol syndrome (FAS), a serious disorder affecting brain function, is the leading preventable birth defect in the U.S., with an estimated incidence rate between 0.5 to 3.0 cases per 1,000 births. A larger number of infants who do not present with the facial features required for a FAS diagnosis, nonetheless, experience alcohol-related neurobehavioral deficits caused by prenatal alcohol exposure (SAMHSA, June, 2004).

While alcohol is usually studied separately from other addictive substances, many people who have addictions may use several other substances, including alcohol, marijuana, cocaine, and heroine. Nineteen million Americans 12 years or older reported using illicit drugs in SAMHSA's 2004 National Survey on Drug Use and Health; this represented just fewer than $8 \%$ of the U.S. population. Marijuana was the most commonly reported illicit drug used (14.6 million) followed by non-medical psychotherapeutic drugs (6 million), pain relievers (4.4 million), tranquillizers (1.6 million), stimulants (1.2 million), and 
sedatives (0.3 million). Table 1 shows the most popular drugs. Crack cocaine, derived from powder cocaine, produces a euphoric high in less than 10 seconds and costs approximately $\$ 100$ per gram. Marijuana is a plant (cannabis sativa) when harvested, dried and smoked causes the effect of relaxation as well as extreme paranoia. Marijuana is sold in multiple ways from one joint to pounds, which could cost up to $\$ 1,500$. Alcohol's chemical makeup consists of ethanol $(\mathrm{CH} 3 \mathrm{CH} 2 \mathrm{OH})$ and is sold in various forms. When drunk, it reduces anxiety and causes drowsiness. Heroin is synthesized from morphine and is a central nervous system depressant and pain reliever. Its costs could be up to $\$ 125$ per gram. Methylenedioxy-y-N-methylamphetamine (MDMA) commonly referred to as Ecstasy, produces profound positive feelings and relaxation. It is usually sold in pill form and can cost approximately $\$ 25$ per pill.

\section{Alcohol and Drug use Trends}

The National Institute on Drug Abuse (NIDA, 2004) and SAMHSA have sponsored several national surveys to track drug use trends since the 1970 s. One of the most widely known is the National Household Survey on Drug Abuse (2004), which interviewed persons age 12 and older about drug and alcohol use. In 1991, the survey was expanded to include civilians living on military installments, in college dormitories, and in homeless shelters. In 1979, 14.1\% of the population age 12 and older reported using an illicit drug in the past 30 days. Between 1999 and 2001, past month illicit drug use for persons age 12 and older 


\section{Table 1}

The Most Popular Drugs Abused, by Names, Chemical Makeup, Cost per

\section{Unit, and Effects on Users, Ranked by Desirability in the Drug Culture}

\begin{tabular}{|c|c|c|c|c|c|}
\hline & $\begin{array}{c}\text { Street } \\
\text { Names } \\
\text { of Drugs }\end{array}$ & $\begin{array}{l}\text { Chemical } \\
\text { Makeup }\end{array}$ & Picture & $\begin{array}{l}\text { Approximate. } \\
\text { Cost per Unit }\end{array}$ & Effects on Users \\
\hline 1 & $\begin{array}{l}\text { Crack } \\
\text { Cocaine } \\
\text { (Coke, } \\
\text { rocks) }\end{array}$ & $\begin{array}{l}\text { A form of } \\
\text { cocaine base, } \\
\text { is derived } \\
\text { from powder } \\
\text { cocaine }\end{array}$ & & \$100/Gram & $\begin{array}{l}\text { Produces a euphoric } \\
\text { effect high in less } \\
\text { than } 10 \text { seconds }\end{array}$ \\
\hline 2 & $\begin{array}{l}\text { Marijuana } \\
\text { (Pot, } \\
\text { weed, } \\
\text { joints, } \\
\text { grass) }\end{array}$ & $\begin{array}{l}\text { From the plant } \\
\text { cannabis } \\
\text { sativa }\end{array}$ & & $\$ 1,500 /$ pound & $\begin{array}{l}\text { Could manifest itself } \\
\text { in various ways, from } \\
\text { relaxation to paranoia }\end{array}$ \\
\hline 3 & Alcohol & $\begin{array}{l}\text { Ethanol, } \\
\mathrm{CH} 3 \mathrm{CH} 2 \mathrm{OH}\end{array}$ & & Various & $\begin{array}{l}\text { Reduces anxiety and } \\
\text { makes people drowsy }\end{array}$ \\
\hline 4 & $\begin{array}{l}\text { Heroin } \\
\text { (smack, } \\
\text { junk, } \\
\text { black tar) }\end{array}$ & $\begin{array}{l}\text { Synthesized } \\
\text { from morphine }\end{array}$ & & $\$ 125 /$ Gram & $\begin{array}{l}\text { A central nervous } \\
\text { system depressant } \\
\text { that relieves pain and } \\
\text { induces sleep. It } \\
\text { produces a dreamlike } \\
\text { state of warmth and } \\
\text { well-being. }\end{array}$ \\
\hline 5 & $\begin{array}{l}\text { MDMA } \\
\text { (Ecstasy, } \\
\mathrm{X}, \text { Adam, } \\
\text { and } \\
\text { Essence) }\end{array}$ & $\begin{array}{l}\text { MDMA (3,4- } \\
\text { methylenediox } \\
\text { y-N- } \\
\text { methylamphet } \\
\text { amine) }\end{array}$ & & \$25/Pill & $\begin{array}{l}\text { Produces profoundly } \\
\text { positive feelings, } \\
\text { empathy for others, } \\
\text { elimination of anxiety, } \\
\text { and extreme } \\
\text { relaxation. }\end{array}$ \\
\hline
\end{tabular}

increased from $6.3 \%$ to $7.1 \%$. In 2001 , an estimated $0.7 \%$ of the population age 12 and older reported using cocaine, including crack, at least once in the past month. Such use peaked in 1979 for 18-25-year-olds at 9.9, in 1982 for 12-17- 
year-olds at $1.9 \%$, and in 1985 for $26-34$-year-olds at $6.3 \%$. In 2001, the percentage of Americans reporting marijuana use at least once in the past month was $5.4 \%$ of the population age 12 and older. Reported use of marijuana in the past month peaked in 1979 for 12-17-year-olds at 14.2\%; for 18-25-year-olds at 35.6\%; and for 26-34-year-olds at $19.7 \%$.

\section{The Prevalence of HIVIAIDS}

This section provides a primer on AIDS—chronicling the prevalence of HIVIAIDS internationally, in the United States, and Kentucky. This section closes by showing the devastating connection between HIVIAIDS, and addiction to AOD. Although there is a substantial body of literature addressing major milestones of the HIVIAIDS pandemic since its beginning (Bawa, 2005; del Rio, 2005; Genuis \& Genuis, 2005; Shilts \& Greider, 2000), discussion will be limited to the above stated issues.

\section{HIVIAIDS Internationally}

Current estimates are that 38 million people were living with HIV infection at the end of 2003 and that the epidemic continues to expand in almost all regions of the world, with approximately 4.8 million new infections in 2003 (Joint United Nations Programme on HIVIAIDS, 2004). The burden of disease in this pandemic is disproportionately high among women and those who live in poverty. The proportion of infected persons who are women has increased steadily so that now more than $50 \%$ of those living with HIV are female. Adolescents and young adults aged 15-24 years account for half of all new infections worldwide, and girls and young women are particularly vulnerable. In Sub-Saharan Africa, 
women account for $57 \%$ of infected adults and $75 \%$ of the infections in young adults. Though a large proportion of HIV-infected adults in the U.S. are men, women now account for $25 \%$ of all HIV infections in North America (CDC, 2004a; CDC, 2004b; Kaiser Family Foundation, 2004).

\section{HIVIAIDS in the United States}

The HIVIAIDS epidemic continues to be a major problem for U.S. citizens with approximately 1 million Americans HIVIAIDS infected (CDC, 2002). According to the Centers for Disease Control and Preventions (CDC, 2002) AIDS incidence increased throughout the 1980s, declined from the mid-1990s through 2001, and increased 2\% in 2002 (over 2001). AIDS prevalence, or the number of persons living with AIDS in the U.S., continues to increase and was estimated to be 384,906 at the end of 2002 (CDC, 2002). Although HIV has historically been most prevalent among men who have sex with men (MSM, Bacon et al., 2006; Catania, Osmond, \& Stall, 2002; Celentano et al., 2006), most new HIV infections are reported among MSM who are also injection drug users. The proportion of HIV cases acquired through heterosexual contact has also increased, and is equal to the proportion of cases attributed to injection drug users (CDC, 2002; Karon et al., 2001).

Some minority groups within the U.S. are also disproportionately affected. For example, approximately $50 \%$ of those living with HIVIAIDS are Black and 10\% are Hispanic (Kentucky HIVIAIDS Surveillance Report, 2002; Zaidi et al., 2005). The geographic distribution of people living with AIDS has also changed as the epidemic has become more generalized. By the end of $2002,39 \%$ of 
persons living with AIDS in the U.S. resided in the South, $29 \%$ in the Northeast, $19 \%$ in the West, $10 \%$ in the Midwest, and 3\% in the U.S. territories (Kentucky HIVIAIDS Surveillance Report, 2002).

Reports of women being infected with HIV has tripled since mid-1980, mainly resulting from heterosexual exposure and secondarily through injection drug use (CDC, 2002). Minority groups are the most affected by HIV associated with drug injection and Blacks and Hispanics account for approximately $70 \%$ of all new U.S. AIDS cases (CDC, 2002).

\section{HIVIAIDS in Kentucky}

The prevalence of HIVIAIDS in Kentucky is comparable to national trends. As of December 31, 2004 there have been 4,119 AIDS cases reported in Kentucky to the Department for Public Health's HIVIAIDS surveillance system. Of these reported cases, only 2,245 were still reported as living as of 2004. In 2003, there were 195 new AIDS cases diagnosed. As of December 2004, 158 new AIDS cases were diagnosed and reported to the Kentucky HIVIAIDS surveillance programs in 2004. Kentucky ranked 31st among the United States in the number of AIDS cases reported in 2002 (7.5 per 100,000).

The Kentucky HIVIAIDS Semi-Annual Report (2004) presents data regarding AIDS cases diagnosed and reported to the Kentucky Department for Public Health, HIVIAIDS Program through December 31, 2004. Kentucky, however, did not report HIV cases until last year and is currently updating its reporting system to reflect both HIV and AIDS. According to state regulation 902 KAR 2:020, Section 7 of the Kentucky Annual Report (KAR), health professionals 
licensed under KRS chapters 311 through 314, health facilities licensed under KRS Chapter 216B and laboratories licensed under KRS Chapter 333 are required to report HIV and AIDS cases to the Kentucky Department for Public Health within five business days of diagnosis. AIDS cases are reported by name, while HIV cases were previously reported by a unique identifier consisting of the person's initials of last and first names, date of birth, and last four digits of their Social Security numbers.

However, the reporting system for HIV cases has changed. On July 13, 2004 new HIVIAIDS reporting requirements were adopted in Kentucky to include reporting for HIV using a confidential name based reporting system. According to 902 KAR 2:020 Section 7, HIV cases are to be reported by name, gender, race, and risk factor as identified by the CDC. Data from the HIV confidential name based reporting system, which was implemented as a result of these requirements, will not be released until a complete evaluation of the system has been completed. HIV tests can be either anonymous or confidential; however, only confidential HIV positive cases are reported to the Kentucky Department for Public Health. This new system of reporting will provide the state with more accurate data on those who are HIV-infected and not just limited to only reporting AIDS cases.

\section{Demographic Trends}

The Kentucky 2004 HIVIAIDS Semi-Annual Surveillance Report (2004), which just accounts for AIDS reported cases (not HIV), indicates that $80 \%$ of all Kentucky AIDS cases reported are male, $20 \%$ female. AIDS cases by race show 
that the majority of infected individuals are White (58\%), with African Americans making up $35 \%$ of AIDS cases while representing only $7.3 \%$ of the state's population (U.S. Census Bureau, 2004). Almost half of the state's AIDS patients (46\%) were reported to live in the North Central region of the state, which includes the Louisville Metro area. Cases reported by risk factors in 2004 indicated that men who have sex with other men are at the highest risk (47\%) followed by intravenous drug users (17\%), and risk factors for $16 \%$ were undetermined. In 2002, the AIDS rate for African-Americans was approximately seven times higher than for whites in Kentucky. The AIDS incidence rate for African Americans has been gradually declining since 2000 with a slight increase observed in 2001. The AIDS rate among white Americans, which had steadily declined since 1996, increased for the first time in 2001 and continued through 2002. Overall, AIDS rates for white Kentuckians has remained relatively stable. The AIDS rates for African-American males in Kentucky are seven times higher than white males in Kentucky and African-American females in Kentucky have AIDS rates 13 times higher than white females in Kentucky (Kentucky 2004 Kentucky HIVIAIDS Semi-Annual Surveillance Report).

In 2002, AIDS was the 22nd leading cause of death for all Kentuckians. AIDS was the 11th leading cause of death in African Americans and the 25th leading cause of death of Whites in Kentucky (Kentucky 2004 HIVIAIDS SemiAnnual Surveillance Report). For African American males in Kentucky, AIDS ranked as the 9th leading cause of death. In 2002, among those ages 25-44, AIDS was the 6th leading cause of death. Among those ages 25-44, AIDS 
ranked as the 2 nd leading cause of death for African American males, 7 th among white males, 5th among African American females, and 11th among white females. In 2002, death rates among 25-44 year old White males and females increased while death rates among 25-44 year old African-American males and females decreased (Kentucky HIVIAIDS Semi-Annual Surveillance Report, 2004).

In 2004 the largest number of AIDS cases (46\%) residing in Kentucky at the time of diagnosis were in the North Central Area Development District (ADD), which includes the Louisville Metro area (Figure 1). The Bluegrass ADD had the second largest number of AIDS cases (19\%) reported in Kentucky, which includes the city of Lexington, followed by the Northern Kentucky ADD with the third largest number of AIDS cases (8\%) reported in Kentucky (Kentucky 2004 HIVIAIDS Semi-Annual Surveillance Report, 2004).
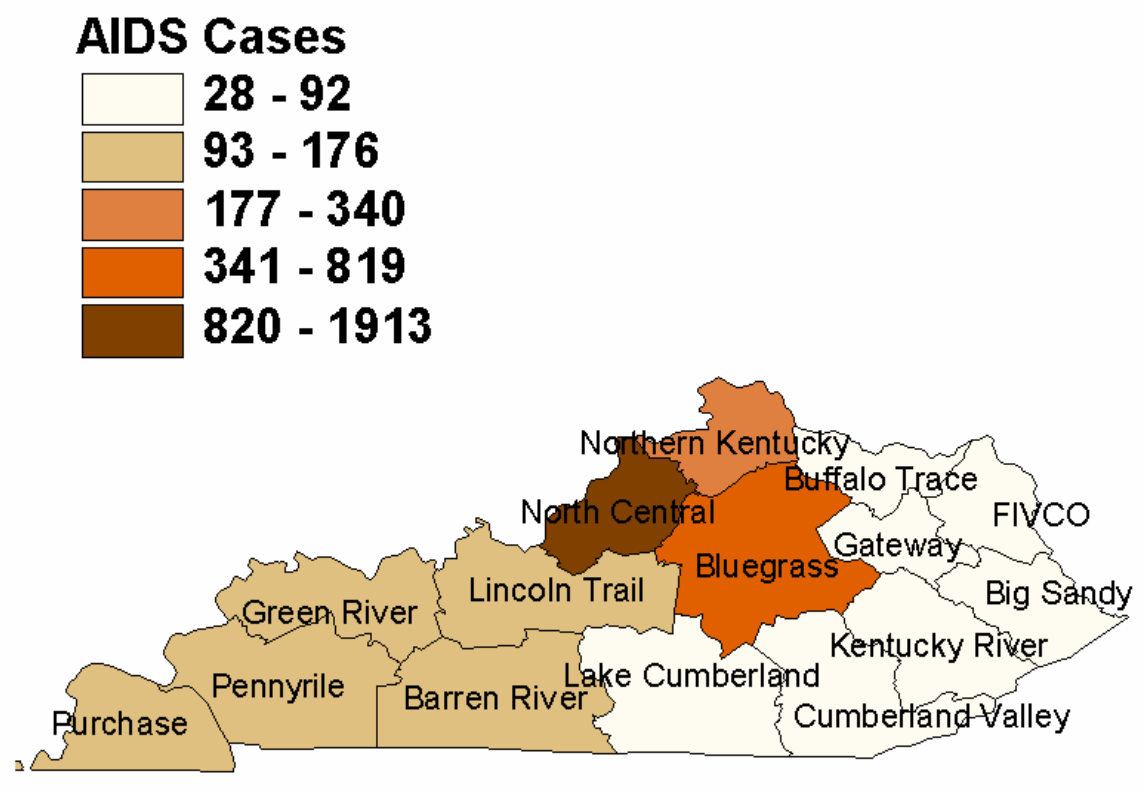

Figure 1. Number of AIDS cases in Kentucky. 
This supports findings that those who use alcohol are more likely to engage in behaviors that place them at higher risk for contracting HIVIAIDS (Metzger, Navaline, \& Woody, 1998; Stein, Hanna, \& Natarajan, 2000); Windle, 1997). There are high rates of intravenous drug users among alcoholics in treatment (Metzger et al., 1998) and drug-related risk behavior, i.e. needle sharing and unprotected sex, increase along with the increase of alcohol ingestion (Stein, Hanna, \& Natarajan, 2000). There is also a link between a history of heavy AOD use (Baseman et al., 1999; Deren et al., 1996; Hansen et al., 2002; Logan et al., 2003; Surratt, Inciardi, Kurtz, \& Riley, 2004) and the tendency toward a lifetime of high-risk sexual behaviors, which include multiple sex partners, unprotected intercourse, sex with high-risk partners, and the exchange of sex for money or drugs (Avins et al., 1994; Boscarino et al., 1995; Windle, 1997).

\section{The Importance of Studying Addiction \& HIVIAIDS Together}

The role played by alcohol consumption as a facilitator of HIVIAIDS infection risk has been the subject of much research. A relationship between alcohol use and HIVIAIDS risk has been documented among men who have sex with men (Bacon et al., 2006; Celentano et al., 2006; \& Koblin et al., 2003), urban minority groups (Norris \& Ford 1999), adolescents (Kerr \& Matlak, 1998), HIVseropositive individuals (Marks, Crepaz, Senterfitt, \& Janssen, 2005), seriously mentally ill persons (Tucker et al., 2003), and non-U.S. populations.

Twenty-nine to $60 \%$ of HIV-infected patients develop an AOD addiction at some point in their lives-a rate roughly three times as high as that of the U.S. 
population (Meyerhoff, 2001). According to Petry (1999), the prevalence of addiction among current HIV-infected individuals is nearly 12\%--approximately twice the rate of the general population.

The connection between alcohol and other drug addiction and HIVIAIDS has been established, including the role of AOD use in the continuing spread of HIVIAIDS. The Center for Substance Abuse Treatment (2002) identified five important issues related to AOD and HIVIAIDS: (a) substance abuse increases the risk of contracting HIV due to the association between the use of dirty needles and engaging in risky sexual behaviors in exchange for drugs and/or money, (b) substance abuse increases risks for obtaining substances while under the influence or while under coercion, (c) substance abuse and HIVIAIDS both serve as potential catalysts or obstacles in the treatment of the other, (d) substance users who inject drugs represent the largest HIV-infected population in the U.S., and (e) putting clients in substance abuse treatment, along with a continuum of care, minimizes the risk of substance abuse and HIV infection (2002). In order to stop the spread of HIVIAIDS without a vaccine, those who are infected with the disease must stop passing it along. One of the best ways to stop the spread of the disease is for patients to enter and engage in treatment that lowers the risks for exposing others.

\section{Treatments}

This section chronicles the history of treatment for alcohol and other drug addictions and the three main levels of treatment. The history of treatment for HIVIAIDS is then described, and finally, the complexity of treating individuals 
unfortunate enough to need treatment for both conditions_-addiction and HIVIAIDS—is briefly addressed. While there are other exclusive bodies of literature regarding addiction to and treatments of specific, individualized substances such as nicotine (i.e. Lancaster \& Stead, 2006; Roozen et al., 2006) or opiate addiction (i.e. Ashworth, 2005; Sorensen et al., 2005) those distinctive addictions are not addressed in this study.

\section{The History of Addiction Treatments}

The addiction treatment field in the U.S. has a history of disagreeing about the best model or design for treating the addicted individual, resulting mainly from the disagreement about the causes of addiction. Alcoholism's causes have been rooted in personal choice (Fingarette, 1988), sociocultural influences (Cahalan, 1987), family of origin pathologies (Steiner, 1971), and social learning (Peele, 1985), as well as biochemical dysfunctions (Milam \& Ketcham, 1981). Alcohol is one of the oldest, most often used drugs. The problems associated with using alcohol are described in the Bible:

Whose heart I filled with anguish and sorrow? Who is always fighting and quarrelling? Who is the man with bloodshot eyes and many wounds? Is it the one who spends long hours in the taverns trying out new mixtures. Don't let the sparkle and the smooth taste of strong wine deceive you. For in the end it bites like a poisonous serpent; it stings like an adder. You will see hallucinations and have delirium tremens, and you will say foolish, silly things that would embarrass you no end when sober. You will stagger like a sailor tossed at sea, clinging to a swaying mast. And afterwards you 
will say. I didn't even know it when they beat me up ... let's go and have another drink. (Proverbs 23: 29-35, The living Bible)

Just as the problems connected to drinking alcohol have a long history, so do the proposed solutions. One of the oldest solutions has been to modify individuals' behavior and moral codes. This moral perspective sees drinking as a willful act that violates socially acceptable norms, but which can be controlled by individual choice (Connors \& Rychtarik, 1989). The moral view of addiction remains prevalent today (just say no) resulting in the civilization of addiction and the everincreasing prison population.

Following the moral viewpoint of addiction was the temperance movement that emphasized controlled use of alcohol. As the use of alcohol began to spread and people in the late $18^{\text {th }}$ century and into the $19^{\text {th }}$ century died from alcoholism, the temperance movement changed from moderation of consumption to total abstinence (Maxwell, 1950). The viewpoint stemming from the temperance movement was that the cause of alcohol problems was the presence of alcohol. The natural progression from this perspective was to ban the manufacture, sale, transportation, and importation of alcohol, better known as the $18^{\text {th }}$ Amendment to the Constitution and the beginning of prohibition. While alcohol consumption decreased under prohibition, the law was difficult to enforce and widely unpopular and ignored.

A few years after the repeal of prohibition, Alcoholics Anonymous (AA) was founded in 1935 by two alcoholics who were attempting to recover on spiritual principles-a stockbroker and a physician. One of the founders, Bill 
Wilson, had experienced a spiritual awakening resulting from his experience with the Oxford Group fellowship, a religious movement that thrived briefly in the 1930s. The Oxford Group meetings consisted of small group discussions where confessions, talking out emotional problems, and praying to God took place (Trice, 1958). While the Oxford movement was centered on a religious conversion, AA (n.d.) began to see alcoholism as an illness-the moral crusade was coming to an end.

Around the same time, the medical community became interested in alcoholism. In an attempt to study alcohol problems through scientific work, the Research Council on Problems of Alcohol was established in New York (Keller, 1976). While the research council did not receive any funds to study the problems associated with alcohol, it did result in de-moralizing the problem and set the stage for the federal government to create a bureaucracy around alcoholism. The first federal fund established to deal with alcohol problems was the National Institute of Alcohol Abuse and Alcoholism (NIAAA) and within a short period of time millions of dollars were directed toward combating alcoholism.

\section{Current Treatments}

Addiction treatment is currently designed to begin with medically supervised detoxification, followed by some type of rehabilitation services lasting from a few weeks up to possibility more than a year. The criteria for diagnoses using the Diagnostic and Statistical Manual of Mental Disorders (DSM-IV) (American Psychiatric Association, 1994), requires the presence of three or more 
of the following: increased tolerance (can hold more and more), withdrawal, drinking alcohol in larger amounts, the desire to cut down the amount of alcohol use, a great deal of time invested in obtaining or using alcohol, reducing social activities that include drinking alcohol, and continued use despite physical or psychological problems.

The three levels of care for the treatment of addiction are inpatient, intensive outpatient (IOP), and outpatient. All three levels include activities such as group and individual counseling, addiction education sessions, basic life skills education, and engagement with 12-step meetings. Inpatient treatment is the highest level of care—residential services lasting approximately one month. Intensive outpatient services may include daily and possibly weekend services lasting several hours per day over a period of many months. Outpatient treatment is the lowest level of care and is designed for those who work and have stable employment and social supports.

The History of HIVIAIDS Treatments

Although the virus was initially identified in the 1980s the infection in human beings probably originated as early as the 1950 s, spreading in an epidemic way in the 1970s (Zhu et al., 1998). While there are many theories concerning the exact origin of HIV, Gao et al.,(1999) recently discovered a subspecies of chimpanzees in Africa carrying the HIV-1 virus, which was introduced to humans and is responsible for the current pandemic. The researchers concluded that hunters were exposed to infected blood. The first cases of AIDS during the 1980s puzzled physicians because healthy young 
homosexual men were showing up in hospitals with the presence of a rare infection found only in severely immunocomprimised people. Several cases were published identifying pneumonia from Pneumocystis carinii, an ordinary organism rarely causing infection, along with invasive Kaposi sarcoma, a strange cancer that was usually localized (Treisman \& Angelino, 2004). In the early years of the disease, treatment focused mainly on palliative care-keeping the patient comfortable. Although HIV infection continues to have a dismal outcome, in the early 1990s, antiretroviral drugs were developed and prescribed. One of the first drugs used was Azidothymidine (AZT), which added about 18 months to the lives of HIV-infected individuals (Treisman \& Angelino, 2004).

As research progressed and new drugs entered the market, pharmaceutical treatments consisted of a cocktail of drugs regimented for effectiveness. This highly active antiretroviral therapy, better known as HAART, had to have $90 \%$ compliance to the regimen in order to be effective (Treisman \& Angelino, 2004). With these antiretroviral therapies, people with HIVIAIDS can have lively, productive lives. The Ryan White Act provides funds for addiction treatment but it is totally separate from medical care. Unfortunately, little is known about the effectiveness of many treatment approaches—one of the reasons for this study.

\section{Combining Addiction and HIVIAIDS Treatment}

Because both of these conditions are complex and chronic by themselves, it is important to have experienced AOD practitioners on staff when treating addicted HIV-infected individuals. Integrating care for addicted HIV-infected 
individuals is, at best, difficult. Regardless of whether they enter medical care or alcohol and drug treatment and due to limited training, providers may disagree on which chronic disease has priority (Patterson et al., 2004). In order to accomplish integrated care for addicted HIV-infected persons, connections must be made between the two providers, which enhance access to care and expansion of integrated services (Selwyn \& O'Connor, 1992).

Alcohol and drug treatment providers should be able to conduct HIV risk assessments, provide basic HIV education and counseling, and provide HIV testing with pre- and posttest counseling (CDC, 1993). The staff within the primary medical care facility should ask questions regarding alcohol and drug use, have cultural competence training, and reinforce the message to patients that any AOD use damages their overall health and is cause for referral to be assessed for alcohol and drug problems (Patterson, 2004). Unfortunately, integrated services are few and far between. While there has been an attempt at medical and alcohol and drug providers working together, this type of recommended care is still nonexistent in the Louisville, Kentucky area.

The next chapter provides a comprehensive review of relevant literature. Retention in treatment and theoretical perspectives are highlighted. 


\section{CHAPTER II}

\section{REVIEW OF RELATED LITERATURE}

This chapter first focuses on treatment retention and completion for both populations under study (those addicted to AOD and persons with HIVIAIDS). Theoretical perspectives are then examined and Motivational Interviewing as an intervention to increase retention is presented. This chapter closes with explication of the gap in the professional literature that this study is designed to address.

\section{Treatment Retention and Completion Linked to Better Outcomes}

Research links treatment retention and completion to lower alcohol use, which in turn, decreases the risk for spreading HIV (e.g., Basso \& Bornstein, 2000; Moos, 2003). Treatment retention and completion have been consistently confirmed to improve outcomes (e.g., Hubbard et al., 1996; Simpson, 1981). Since time in treatment and treatment completion are generally associated with more successful outcomes, identification of factors related to treatment retention is important. Unfortunately, however, treatment dropout in the U.S. is also a wellknown phenomenon. According to Hubbard et al.,(1989), approximately $82 \%$ of the clients in outpatient, drug free programs drop out before completing treatment. More recent findings of high dropout rates across treatment modalities 
indicate that clients usually do not remain in treatment for more than a couple of weeks (Anglin \& Hser, 1990).

\section{Rationale for Studying Retention}

Retention and completion of addiction treatment have been widely recognized as factors contributing to improved post treatment alcohol and other drug abstinence. While adaptations of Motivational Interviewing (Miller \& Rollnick, 2002) have demonstrated promise in improving treatment adherence, including retention (Zweben \& Zuckoff, 2002), no studies on methods were found to improve retention and completion among those who were HIV-infected. Given the established health threat related to the spread of AIDS by those who are dually diagnosed with HIV-infected and actively abusing alcohol, this is a serious concern (Basso \& Bornstein, 2000). Thus, the overall purpose of the study is to test the effects of up to five motivational interviewing sessions on the retention rates for addicted HIV-infected individuals entering an intensive outpatient alcohol and drug treatment program.

\section{Retaining HIV-Infected Alcohol Dependent Individuals in Treatment}

Although Zweben and Zuckoff (2002) made a case for using Motivational

Interviewing with AOD addicted individuals in order to improve their retention and completion, there is an absence of empirically based practice methods that focus on retaining HIV-infected alcohol-dependent individuals in treatment. The majority of studies of HIV-infected individuals with addictions center on retention in methadone maintenance programs. 
While past studies addressed HIV-infected individuals' retention in care services, few dealt specifically with retaining addicted individuals in alcohol and drug treatment settings. The efficacy of motivational interviewing with HIVinfected alcohol dependent individuals has not been evaluated.

\section{Hypotheses}

Two hypotheses were posed for this study which pertained to the paucity of research on the potential of $\mathrm{Ml}$ to increase number of days in treatment: Therefore, the hypothesis posed and tested are: Up to five booster motivational interviewing sessions during the first two weeks of treatment increases (a) days in IOP treatment, and (b) completion rates in an intensive outpatient alcohol and drug treatment program in a Volunteers of America treatment program.

Theoretical Perspectives on Treatment Retention

This section provides theoretical perspectives regarding treatment retention. It begins with (a) Carl Rogers' perspective, (b) Prochaska's Transtheoretical Stages of Change Model, (c) Miller \& Rollnick's perspective of Motivational Interviewing, (d) designing an intervention using Motivational Interviewing, and ends with (e) the gap in knowledge.

\section{Carl Rogers' Therapy and Therapeutic Relationship}

Motivational Interviewing was birthed out of Carl Roger's approach to counseling. Carl Rogers' main idea about humanity is that every one of us has one ultimate motivating force - self-actualization. He defined this event as the 
inherent tendency of the organism to develop all its capacities in ways that serve to maintain or enhance the organism $(1951,1961, \& 1980)$.

According to Rogers we are born with a positive valuing process that enhances and maintains the positive things in our lives, and devalues negative experiences that stagnate our growth potential. With this internal process that is part of our inherent design, we trust that they intend to serve us well. Rogers concluded that our worlds are products of our own making (our realities) and that in order for someone else to understand our real reality they must attempt to place themselves in our frame of reference $(1951,1961, \& 1980)$. Once we understand ourselves, we seek positive regard for that self. People learn to need others and to be needed, loved, prized, and accepted. These needs are addictive and can become the most important thing in becoming a person.

For instance, when parents respond to children's behaviors with positive reflection, the children see that their behavior evoked a pleased parent and they try to do it again. But if parents respond negatively, children see their loving relationships with their parents weakening. Before long, as children grow, they see themselves as others regard them. This results in individuals seeing themselves as more or less worthy, depending on the responses they received from their parents and others.

Individuals with maladjusted conditions of worth are threatening to themselves. Because we all deserve full self-actualization and to become whole persons, if our behavior is conflicted with the self we like and the self we dislike, 
then we have divided personalities that can result in dysfunction $(1951,1961, \&$ 1980).

The most important ingredient for therapy, according Rogers, is the therapeutic relationship. As stated earlier, Motivational Interviewing's techniques are founded in Rogers' therapy and his relationship beliefs with clients. He uses terms such as unconditional positive regard, empathy and genuineness. Without the therapist succeeding in these relationship issues, Rogers' therapy falls apart. Because of his theory behind personality and people seeking self-actualization, if the therapy session's atmosphere does not provide unconditional positive regard for the client, then harm will result.

\section{Transtheoretical Stages of Change Model}

The Transtheoretical Stages of Change Model (Prochaska \& DiClemente, $1982,1984)$ described a behavioral change model that can be generally applied to explain treatment retention. Their work consists of how and why people change on their own as well as with some type of professional assistance. They set out to describe a set of predictable stages through which people travel in the course of altering addicted behavior: Preconception, Contemplation, Determination, Action, and Maintenance. These stages of change, however, are not without criticism. In a review of research on the transtheoretical model, Littell and Girvin (2002) observed that empirical evidence suggests that the proposed stages of change are not discrete, and there is little empirical evidence showing sequential transitions through the stages. The researchers proposed that change can come about swiftly, often as a result of life events or external pressures, 
rather than a progression through stages. Nonetheless, the transtheoretical model is widely accepted and prescribed due to its useful heuristic view of change. Within this approach, motivation can be seen as a client's present state or stage of readiness for change. Several researchers have demonstrated that an adaptation of Motivational Interviewing can be effective at influencing stages of change including treatment compliance and retention (e.g. Zweben \& Zuckoff, 2002).

Prochaska and DiClemente $(1982,1984, \& 1986)$ created five criteria for the transtheoretical model. First, a sophisticated integration must respect both the fundamental diversity and essential unity of psychotherapy systems. Second, the model should emphasize empiricism by measurable variables, and be validated. The third criterion was to account for how some people recover from clinical disorders without the help of professionals. Fourth, the model should generalize to a broad range of human problems. And finally, the transtheoretical model should encourage psychotherapists to be innovators, rather than simply borrowing from other systems (Prochaska, Norcross, \& DiClemente, 2002).

\section{Stages of Change}

Five stages of change have been conceptualized for a variety of problem behaviors: Precontemplation, Contemplation, Preparation, Action, and Maintenance (Prochaska \& Norcross, 2003). One of many reasons for using this in an AOD program is its natural connection with the 12 steps of Alcoholics Anonymous (AA). While there will be a discussion of these theories later, the 12 steps of AA (n.d.) are listed below to show how they would fit these stages. 
Precontemplation is the stage in which people are not intending to take action in the foreseeable future, usually measured as the next six months. People may be in this stage because they are uninformed or under-informed about the consequences of their behaviors. Or they may have tried to change a number of times and become demoralized about their ability to change. Both groups tend to avoid reading, talking or thinking about their high-risk behaviors. They are often characterized in other theories as resistant or unmotivated or as not ready for treatment. Traditional therapeutic programs are often not designed for such individuals and are not matched to their needs (Prochaska, Norcross, \& DiClemente, 2002).

Contemplation is the stage in which people are intending to change in the next six months. They are more aware of the pros of changing but are also acutely aware of the cons. This balance between the costs and benefits of changing can produce profound ambivalence that can keep people stuck in this stage for a long time. Those finding themselves in this stage are characterized as chronic contemplators or behavioral procrastinators. These people are also not ready for traditional action oriented programs and could account for many treatment dropouts (Prochaska, Norcross, \& DiClemente, 2002).

Preparation is the stage in which people are intending to take action in the immediate future, usually seen as the next month. They have typically taken some significant action in the past year. These individuals have a plan of action, such as joining a health education class, consulting a counselor, talking to their physicians, buying self-help books. or relying on self-change approaches. These 
are the people who should be recruited for action-oriented smoking cessation, weight loss, or exercise programs (Prochaska, Norcross, \& DiClemente, 2002). . The first three AA steps are undertaken in this stage:

1. We admitted we were powerless over alcohol - that our lives had become unmanageable.

2. We came to believe that a power greater than ourselves could restore us to sanity.

3. We made a decision to turn our will and our lives over to the care of God as we understood Him.

Action is the stage in which people have made specific overt modifications in their life-styles within the past six months. Since action is observable, behavior change often has been equated with action. But in the Transtheoretical Model, Action is only one of five stages. Not all modifications of behavior count as action in this model. People must attain a criterion that scientists and professionals agree is sufficient to reduce risks for disease. In smoking, for example, the field used to count reduction in the number of cigarettes as action, or switching to low tar and nicotine cigarettes. Now the consensus is clear--only total abstinence counts. The Action stage is also the stage where vigilance against relapse is critical (Prochaska, Norcross, \& DiClemente, 2002). AA Steps 4 through 9 are to be completed in this stage:

4. We made a searching and fearless moral inventory of ourselves.

5. We admitted to God, to ourselves, and to another human being the exact nature of our wrongs. 
6. We sere entirely ready to have God remove all these defects of character.

7. We humbly asked Him to remove our shortcomings.

8. We made lists of all persons we had harmed and became willing to make amends to them all.

9. We made direct amends to such people wherever possible, except when to do so would injure them or others.

Maintenance is the stage in which people are working to prevent relapse but they do not apply change processes as frequently as do people in action. They are less tempted to relapse and increasingly more confident that they can continue their change (Prochaska, Norcross, \& DiClemente, 2002). AA Steps 10 - 12 are completed in the Maintenance stage:

10. We continued to take personal inventory and when we were wrong promptly admitted it.

11. We sought though prayer and meditation to improve our conscious contact with God as we understood Him, praying only for knowledge of His will for us and the power to carry that out.

12. We have had a spiritual awakening as the result of these steps; we tried to carry this message to alcoholics and to practice these principles in all our affairs.

\section{Prochaska's Therapy}

There is an attempt to combine the process of change and the stage. Once the stage of change is identified in a client, then the process is applied. Prochaska has specific recommendations for the process of change during each stage. For example, if a client was in the Precontemplation or Contemplation 
stage, the therapist would attempt to raise the client's consciousness and/or dramatic relief (Prochaska \& Norcross, 2003). Helping the client become more aware of the problem and get some emotional relief would move them into the next stage. For the Contemplation stage specifically, environmental reevaluation and self-reevaluation are used. As clients become more aware of their problems, they are more open to reevaluating their values and actions. The Preparation stage utilizes self-liberation due to the client's readiness to change. They need to know that they have autonomy to change their lives, which is associated with self-efficacy. Action and Maintenance stages use contingency management, counter conditioning, and stimulus control (Prochaska \& Norcross, 2003).

\section{The Therapeutic Relationship}

The transtheoretical psychotherapist is viewed not as an expert having all of the answers, rather an expert about change. Because some of Prochaska's research studied how people changed without seeking professional services, the relationship is based on the assumption that people have the ability and capability to change. According to Prochaska, the relationship with the client depends on the client's current stage (Prochaska, Norcross, \& DiClemente, 2002). For example, the relationship with Precontemplators should be that of a nurturing parent who allows for independence. Contemplators would create a Socratic or teacher position in that the therapist would encourage insight into the problem's conditions. Working with clients in the Preparation stage is like coaching a specific game plan. A consultation relationship would be used for the 
Maintenance stage. This is another reason to use some of the skills of motivational interviewing.

\section{Motivational Interviewing}

Motivational interviewing (Miller \& Rollnick, 2002) is a proven practice method that has been shown to be as effective as CBT and TSF methods, yet much briefer and time limited. For example, Project MATCH researchers (Project MATCH Research Group 1993, 1997a, 1997b), in a large and highly respected randomly controlled trial $(n=1,726)$ concluded that an adaptation of motivational interviewing, MET, delivered in four 1-hour weekly sessions (Miller \& Rollnick, 1991) was as effective as cognitive behavioral therapy (CBT) (1997a) or twelvestep facilitation (TSF) methods (1997b) delivered across 12 weekly one-hour sessions. Although the adaptation of MI had one-third the number of sessions as CBT or 12-Step clients, the number of days using alcohol in the year following treatment was substantially the same across all three methods (Glaser et al., 1999).

MI provides an approach to explore and resolve ambivalence about recovery. As such, MI may offer a common ground on which both AOD treatment field and health-care providers may be able to unite and collaborate to ensure appropriate care of HIV-infected individuals who are abusing substances. The logic behind using MI with this clientele is that replicated clinical trials have demonstrated what it is a brief intervention (1 to 4 sessions) that is effective at improving substance use outcomes as well as treatment retention and compliance (Miller \& Rollnick, 2002; Zweban \& Zuckoff, 2002). Miller and Rollnick 
(2002) defined Ml as a way of being with people and a set of clinical methods that can be taught and learned. MI involves the application of four basic principles: (a) expressing empathy, (b) developing discrepancy, (c) rolling with resistance, and (d) supporting self-efficacy, thus enhancing intrinsic motivation related to initiating some change to a healthier behavior. MI matches specific treatment strategies to the client's is stage of change (Prochaska \& DiClemente, 1982).

\section{Designing a Motivational Interviewing Intervention}

Denial, defensiveness, and resistance are attributes of substance abusers and can be barriers to effective treatment. However, research has not supported the conclusion that addicted persons, as a group, have abnormally robust defense mechanisms (Miller, 2000). There could be several reasons for this belief, the first being that exceptionally difficult clients are elevated to become models of usual responses. The term "denial" is often used to describe lack of compliance or motivation among substance users, whereas the term "motivation" is reserved for concepts like acceptance and surrender (Kilpatrick et al., 1978; Nir \& Cutler, 1978; Taleff, 1997). According to Miller and Rollnick (1991), clients who disagree with clinicians, who refuse to accept clinicians' diagnoses, and who reject treatment recommendations are usually labeled as being in denial.

A second explanation is that behaviors viewed as normal in ordinary individuals are labeled as pathological when observed in addicted populations (Orford, 1985). Many people use denial, resistance, arguing, and/or rationalization as a common defense mechanism to protect themselves 
emotionally (Brehm \& Brehm, 1981). Aggressive confrontation generally evokes outright denial. Motivational Interviewing avoids the pitfalls of direct confrontation and not allowing the client to have some selection in treatment goals. MI provides a constructive type of therapeutic confrontation thereby helping clients assess the reality of their behaviors, reconnect with their personal goals, and recognize discrepancies between current behaviors and desired ideals (Ivey et al., 1997). Nearly every client coming into the intervention will have some common defense mechanisms which will be dealt with by using the principles of Ml, i.e. focus on client competencies and strengths, refrain from labeling, and create therapeutic partnerships for change using empathy rather than authority and power.

\section{Intervention Development}

Rounsaville, Carroll, and Onken (2001) suggested that intervention development begins with selection of an accepted theory or model to guide the developers. Although MI has not been used with HIV positive patients or to improve retention in an IOP alcohol treatment program, our approach is consistent with Rounsaville et al.'s suggestion in that Ml already stands as a proven practice that can be adapted to treatment retention (Zweben \& Zuckoff, 2002). MI has repeatedly demonstrated success in advancing clients through the stages of change in several randomly controlled trials (Burke, Arkowitz, \& Dunn, 2002). More specifically, Miller and Rollnick (1991) defined motivation as "the probability that a person will enter into, continue, and adhere to a specific change strategy" (p.19), and prescribed MI principles to increase and sustain motivation to change. Interventions such as Motivational Interviewing (or adaptations using 
these principles), have demonstrated promise in increased treatment completion and have been shown to be an effective approach for engaging, treating and retaining individuals with $A O D$ addictions.

Zweben and Zuckoff (2002) reviewed 21 studies that assessed treatment outcomes and adherence to treatment and found that a majority of the controlled studies (12 of 21), using adaptations of motivational interviewing produced significant positive effects on treatment adherence including treatment retention. As a result, Zweben and Zuckoff (2002) reported that "findings of adherence effects in the preponderance of studies leave us cautiously optimistic about motivational interviewing as an add-on adherence intervention" (p. 306).

Miller and Rollnick (1991) contended that motivation is necessary to proceed through stages of change, and identified several research-based clinical principles and strategies to elicit intrinsic motivation. Walizter, Dermen, and Connors (1999) reviewed the MI literature and supported Ml's effectiveness.

Zweben and Zuckoff (2002) concluded that it is necessary to separate the MI intervention process into two distinct motivational problems that must be targeted and successfully resolved in order to improve treatment adherence: (a) alcohol problem acceptance, and (b) alcohol treatment acceptance (Daley et al 1998). Whereas problem acceptance is focused on raising intrinsic motivation to engage in change strategies related to client's alcohol dependence, treatment acceptance involves facilitating motivation and commitment related to treatment adherence. 
Commitment and Action related to problem acceptance must be in place prior to focusing MI on treatment acceptance. Zweben and Zuckoff (2002) noted that while there are risks associated with problem acceptance, i.e., misperceptions, misunderstanding or uncertainties about the presenting problem, treatment acceptance risk factors, i.e. misperception about treatment needs, financial or family hardships and stigmas, these can be ameliorated with MI skills. Zweben and Zuckoff (2002) provided an exploratory framework for addressing adherence, specifically for problem acceptance and treatment acceptance, which was used in designing the booster intervention herein.

The Gap in Knowledge

According to SAMHSA (n.d.), women, adolescents, young adults, and minorities continue to be under-represented in clinical services because of social, cultural, and geographic barriers. This lack of involvement in clinical services diminishes access to quality health care, hampers widespread adoption of available preventive approaches, limits safe and effective management of HIV treatment and associated complications, and jeopardizes the ability of researchers to generalize findings to those most in need. As a result, when applying for SAMHSA research funds they require a planned attempt at recruiting under-represented subjects into the study.

By not excluding any subjects in this study for reasons like homelessness, criminal justice involvement, psychiatric histories, or any other potential problems related to excused subjects for research designs (see Project MATCH Research Group 1997a), as well as purposefully including HIV-infected 
individuals, this dissertation will test the effects of an intervention with individuals who seldom have the opportunity to be involved in research: The primary scientific gap in knowledge is the specific utilization of a Motivational Interviewing intervention with AOD addicts who are also HIVIAIDS positive. While MI has been studied using a variety of subjects in multiple settings, i.e. medication compliance (Adamian et al., 2004; Parsons et al., 2005; Safren et al., 2001), and HIV risk reduction (Harding et al., 2001; Parsons, 2005), evidence-based research is lacking on those who suffer from the dual problems of AOD addiction and HIV-infected. 


\section{CHAPTER III}

\section{METHODOLOGY}

In September 2002, the Volunteers of America's (VOA) intensive outpatient (IOP) clinic in Louisville, KY received funding under SAMHSA to enhance its addiction services for HIV-infected and high-risk populations-the gap in knowledge previously identified. The new funding allowed VOA's IOP program to expand its existing treatment services and treatment outcome research infrastructure. The program increased its original staff of one certified alcohol and drug counselor (CADC) and one case manager to two additional CADCs, two case managers, two associate counselors, and a child advocate to monitor the children while their parents/guardians received treatment. The IOP program is funded through 2007. As part of their IOP evaluation, VOA personnel, as well as University of Louisville evaluators, obtained base line, 6-month and 12-month data with an $80 \%$ follow up requirement. Infrastructure and protocols were in place for obtaining consent, substance abuse and safer sex outcome measures, location and followup at six months after intake, and data entry.

This chapter is organized to first bring the reader into (a) the context of the dissertation study. A preliminary study had just been completed that is briefly described. Then (b) a purpose statement is provided, followed by the (c) research design section that includes the consent procedure, inclusion criteria, 
and how clients were assigned to the treatment and comparison groups. The (d) protocol includes subsections for the comparison and treatment groups, and the operationalization of all variables. The research design section closes with a brief review of analyses conducted, and limitations of the study.

\section{Retention in IOP Prior to Current Study}

During the first year of the Volunteers of America's intensive outpatient clinic, the vast majority of HIV-infected clients who entered the IOP program dropped out of treatment well before completing, and the number of sessions attended was low. The program under study was designed for 26 weeks of primary treatment followed by approximately 26 weeks of aftercare, and includes a total of approximately 130 treatment sessions prior to completion. The IOP clients attend five days a week, Monday through Friday, approximately four hours per day. The total number of male clients entering the program the first year (2003) was 48, with 27 of those being African-Americans and 21 White. Thirtyseven were HIV-infected at the time of admission while 11 reported not being HIV-infected. Means indicate that HIV-infected men dropped out of IOP after only 13.8 days $(S D=18.74)$ compared to non-infected men dropping out after 19.9 days $(S D=27.16)$. Although a notable difference was observed between infected and non-infected clients, the difference was not statistically significant $\left(\mathrm{t}_{(46)}=\right.$ $.859, \mathrm{p}=.395)$.

A preliminary study at an intensive outpatient substance abuse treatment program for those infected with HIV and served by VOA of Kentucky and Tennessee's Intensive Outpatient Clinic, yielded high rates of treatment dropout 
Although many agreed to and entered treatment, most abandoned treatment soon afterwards, which prompted this study. It is hypothesized that up to five additional "booster" sessions of an adaptation of motivation interviewing along with intensive outpatient alcohol and drug treatment services will increase days in treatment (retention and completion) among these dually diagnosed (substance dependence and HIV-infected) individuals who were active in the intensive outpatient treatment program within VOA in Louisville, KY. This dissertation was a pilot study with posttest only comparison groups and sequential assignment to treatment and comparison groups. An adjustment was made to balance the groups in terms of HIV positive clients-a deviation from strict random assignment. The intervention in the treatment group $(n=50)$ consisted of IOP + up to five additional MI booster sessions, and clients in the comparison group ( $\mathrm{n}$ $=56)$.

\section{Purpose Statement}

The purpose of this study was to test the effects of up to five add on booster MI sessions (an adaptation of MI intervention, Miller \& Rollnick, 2002) during the first two weeks of treatment-the time when most dropouts occur. The object is to learn whether these additional MI sessions will help to increase rates of treatment retention and completion in an intensive outpatient addiction program with alcohol and other drug (AOD) addicted as well as individuals who are also HIV-infected AOD. This research built upon existing research infrastructure, and expanded an ongoing treatment longitudinal outcome study 
(sponsored by SAMHSA-Center for Substance Abuse Treatment [CSAT] TI03008) of individuals assessed as high risk for HIV or HIV-infections.

The following steps have been completed as part of the CSAT study that has been underway since late 2003: (a) outreach workers have been trained in MI and have been engaged in regular weekly supervision since October, 2003, and (b) basic demographics and personal information to describe the sample and treatment outcome measures were collected since the beginning of the study. The dissertation represents the next step in intervention development described by Rounsaville et al.,(2001), a stage 1b, a small, randomly controlled pilot study of 15 to 30 subjects per group, treatment and comparison.

\section{Research Design}

The research design is posttest only comparison groups: $\begin{array}{ll}\mathbf{X} & \mathbf{0}_{1}\end{array}$

01

where $\mathbf{X}$ represents the treatment of up to five additional (booster) MI sessions within the first two weeks of IOP sessions for the treatment group of alcohol dependent people who could also be HIV-infected, and $0_{1}$ represents posttests, or outcome measures (Campbell \& Stanley, 1963). This was an intent to treat study, meaning that subjects who were assigned to the treatment group were analyzed, even if they did not follow through to attend any of the MI sessions. The comparison group consisted of alcohol dependent people and who could also be HIV-infected, and who had the same posttests but not the intervention $(\mathrm{X})$, the additional MI booster sessions. All clients were AOD dependent, 
received the intensive outpatient intervention, and were invited to participate in the study (Appendix A).

\section{Consent}

The existing consent form (required by SAMSHA-CSAT) and the University of Louisville's Human Subjects Protection Program Office's Institutional Review Board (IRB) was amended to reflect the up to five additional MI sessions (Appendix B). Subjects were either assigned to the additional motivational counseling treatment condition or the comparison group consisting of the standard IOP services.

\section{Inclusion Criteria}

Subjects (a) were 18 or older, (b) were diagnosed alcohol dependent according to supporting documentation from referral sources or via the Addiction Severity Index (ASI; Fureman, Parikh, Bragg, \& McLellan, 1990; McLellan, Lubrosky, Cacciola, \& Griffith, 1985), (c) could read and understand English sufficiently to complete informed consents and data collection forms, and (d) agreed to engage in intervention activities in the VOA's IOP program.

\section{Assignment to Groups}

Participants were assigned to treatment and comparison groups in a sequential manner. The first eligible person was assigned to the treatment group, the next eligible participant to the comparison group, thus altering until sample size was achieved. Only the MI counselor who provided the MI booster intervention was knowledgeable of the assignment. The client and IOP staff were masked or blind to the assignment, which could have resulted in an unintended 
intervention or treatment diffusion that could have affected the results of the study.

\section{Protocol}

The protocol for the comparison group is first described, then the procedures for the treatment group. All subjects received the IOP services as described here for the comparison group.

\section{Comparison Group and IOP for all Subjects}

The comparison group, those receiving the standard treatment of the VOA's IOP program services, received all usual and customary services rendered by the VOA program. The only difference between the treatment and comparison groups was the additional MI sessions.

Treatment was provided by the VOA IOP program and consisted of weekly individual and group counseling sessions five days a week over a sixmonth period. All clients admitted to the VOA IOP program adhere to a rigorous weekly schedule consisting of 12-step educational sessions, drug refusal skills, life skills, treatment planning, and group therapy. Group therapy is largely focused on engaging clients in twelve-step recovery using a highly structured twelve-step facilitation method that is fundamentally grounded in the AA literature. IOP clients also must attend a minimum number of Alcoholics Anonymous meetings during the course of treatment (usually 5 meetings weekly). All counselors are certified alcohol and drug counselors (CADC) or within a year of obtaining certification. 


\section{Treatment Group}

Once subjects were admitted to the program and volunteered to be in the study the MI counselor was notified. An attempt was made to schedule the first intervention session for the treatment group the following day, which would have been the first full day of IOP. MI sessions were available only to those in the treatment group and were conducted between regularly scheduled IOP counseling or educational meetings. At the beginning of the first MI session subjects were asked if they understood the consent form and whether they had any questions. Subjects in the treatment group were reminded that they were selected to receive additional counseling sessions in order to improve treatment retention and completion.

The Ml counselor placed less prominence on a manualized approach to MI, rather following Miller and Rollnick's (2002) suggestion of remaining in the spirit of motivational Interviewing. Miller and Rollnick concluded after several years of experience, that "... we have found ourselves placing less emphasis on techniques of motivational interviewing and ever greater emphasis on the fundamental spirit that underlies it" (p. 33). Motivational interviewing consists of two phases. Phase 1 focuses on identifying and strengthening clients' existing motivation for change, and Phase 2 seeks to consolidate clients' commitments to change (Miller \& Rollnick, 1998).

Each session's fundamental framework consisted of the counselor focusing on Miller and Rollnick's (2002) suggestion of client collaboration, evocation, and autonomy. The counselor avoided an authoritarian relationship, 
instead, communicating in a partner-like relationship. The session also steers clear of any attempt to insert insight or education, but elicits clients' intrinsic motivation. The final key component of remaining in the spirit of $\mathrm{MI}$ is the awareness that change is ultimately the responsibility of the client (Miller \& Rollnick, 2002).

Because sessions were addressing treatment adherence, the counselor, while remaining in the spirit of MI, followed Zweben and Zuckoff's (2002) strategies of treatment nonadherence (Appendix C). The counselor delivering the intervention was a Ph.D. psychologist who has received extensive training and supervision in motivational interviewing and has been using MI for 7 years.

\section{Operationalization of Variables}

The main dependent variable is the number of days in treatment. All data were collected by the administrative assistant-the demographics in the intake process (four items) and days in treatment when clients either completed the program or ceased to return. The researcher entered the data into the Statistical Package for the Social Sciences (SPSS), and then rechecked the entries.

The following section describes variables that encompass demographic variables included age, gender, race, and HIVIAIDS status. Subjects' ages were provided in years at the date of admission. There are two categories of gender, male and female. Four categories were used to describe the race of participants: African-American, Caucasian, Native American and Hispanic. HIVIAIDS status consisted of self-reported HIVIAIDS negative and positive. The number of MI sessions received by the treatment group was the actual number of $\mathrm{MI}$ sessions 
attended by each subject ( 0 to 5 ). Operationalization of the two primary dependent variables consisted of the actual number of IOP sessions attended ( 0 to 119 over six months $)$ and treatment completion $(0=$ No; $1=$ Yes, completed with staff approval).

Supplemental variables were also used to assess the MI intervention dose levels. Subjects in the treatment group could receive up to five MI sessions during the first two weeks. These sessions (doses) were dichotomized as below and above the median number of $\mathrm{Ml}$ sessions (2) which resulted in 0 to $2 \mathrm{MI}$ sessions $=$ Low dose $($ recoded as 0$)$, and 3 to 5 sessions $=$ High dose $($ recoded as 1).

A counselor's perception of severity was determined by whether subjects were excluded from or included in the Government's Performance and Results Act (GRPA). Programs receiving funds from SAMSHA-CSAT are required to enter client data into the GPRA system at three points in time (baseline, and 6 and 12 months post baseline). Once subjects are entered into the GPRA system, an $80 \%$ followup rate is mandated. Those subjects evaluated at admission to be high risk to locate at followup are not entered into the GPRA system, thereby indicating subject instability. In other words, more severe is seen as those who are more unstable and least likely to be found for following up, as required by GPRA. Factors considered by intake counselors included poor health, recently hospitalized, dying, homeless or in shelters, left town, in jail or running from authorities, and no evidence of collateral contacts. A dichotomous variable $(0=$ 
No; $1=$ Yes, Severe) was created to reflect participants' entrance into GPRA. All variables are operationalized in Table 2.

Table 2

Variable Categories

\begin{tabular}{|c|c|c|c|}
\hline \multicolumn{2}{|r|}{ Variable } & $\begin{array}{c}\text { Operationalization of } \\
\text { Independent Variables }\end{array}$ & Data Level \\
\hline 1 & Age & Actual age in years & Ratio \\
\hline 2 & Gender & $\begin{array}{l}0=\text { Male } \\
1=\text { Female }\end{array}$ & Nominal \\
\hline 3 & Race & $\begin{array}{l}1=\text { African American } \\
2=\text { Caucasian } \\
3=\text { Native American } \\
4=\text { Hispanic } \\
\end{array}$ & Nominal \\
\hline 4 & HIV Status & $\begin{array}{l}0=\text { HIV-Negative } \\
1=\text { HIV-Positive }\end{array}$ & Nominal \\
\hline 5 & $\begin{array}{l}\text { Number of Ml } \\
\text { Sessions }\end{array}$ & Actual number of sessions & Ratio \\
\hline \multicolumn{4}{|c|}{ Primary Dependent Variables } \\
\hline 6 & $\begin{array}{l}\text { Number of IOP } \\
\text { sessions attended }\end{array}$ & $\begin{array}{l}\text { Actual number of IOP sessions } \\
\text { attended }\end{array}$ & Ratio \\
\hline 7 & Completed IOP & $\begin{array}{l}0=\text { Did not complete } \\
1=\text { Completed }\end{array}$ & Nominal \\
\hline \multicolumn{4}{|c|}{ Supplemental Variables } \\
\hline 8 & $\begin{array}{l}\text { MI Dose (number } \\
\text { of MI sessions) }\end{array}$ & $\begin{array}{l}0=\text { Below Median } \\
1=\text { Above median }\end{array}$ & Nominal \\
\hline 9 & Client Severity & $\begin{array}{l}0=\text { Entered into GPRA } \\
1=\text { Not Entered into GPRA }\end{array}$ & Nominal \\
\hline
\end{tabular}

\section{Data Analysis}

Data analysis began with examining sample demographics, plots and histograms of key variables. Tests of between group differences were conducted to assess whether groups were comparable (chi square for dichotomous and categorical variables, $t$-test for continuous variables). The characteristics of subjects who were HIVIAIDS positive were described and key variables 
analyzed. Three additional supplemental analyses were conducted to attempt to explain results of the main hypotheses. 


\section{CHAPTER IV}

\section{RESULTS}

This dissertation tested the effects of a motivational intervention on treatment retention of 106 clients who were addicted to alcohol and other drugs (AOD) and enrolled in an intensive outpatient treatment program. For the purposes of this study, retention was operationalized as both a continuous variable (number of sessions attended prior to discharge from the program), and a dichotomous variable representing completion status (did or did not complete the treatment program). Description of the sample is followed by reporting results of testing two hypotheses, first among the entire sample $(n=106)$ and then among those who were HIV positive $(n=28)$.

\section{Sample Description}

Table 3 describes the sample in terms of age, gender, race and HIV status by comparison group $(n=56)$, treatment group $(n=50)$ and in total $(n=$ 106). Fifty subjects were sequentially assigned to the treatment condition, and 56 to the comparison group. Subjects' mean age was 35 years with a range of 19 to 63 years. The sample was approximately evenly split in terms of gender with $51.9 \%$ women. The sample was racially balanced with approximately $47 \%$ of the sample reporting that they were African American, $49 \%$ white, and $4 \%$ Hispanic 
or Native American. The vast majority of the sample were HIV negative (73\%), and $26 \%$ reported that they were HIV positive.

No significant differences were observed in a comparison of the groups using $t$-tests on age and chi-square on race, gender, and HIV status, suggesting that the groups were similar. As Table 3 indicates, the average age of both groups was approximately 35 years. Of the 55 females entering the study, approximately half, 26, were in the treatment group. Twenty-four of the 51 males in the study were assigned to the treatment group. The racial mix and HIVIAIDS status were also equally distributed. None of the demographic differences resulted in statistically significant findings.

\section{Table 3}

Baseline Characteristics of Respondents $(n=106)$

\begin{tabular}{|c|c|c|c|}
\hline & $\begin{array}{c}\text { Treatment }(n=50) \\
\text { Mean }(S D)\end{array}$ & $\begin{array}{c}\text { Comparison }(n=56) \\
\text { Mean }(S D)\end{array}$ & Total $(n=106)$ \\
\hline \multicolumn{4}{|c|}{ 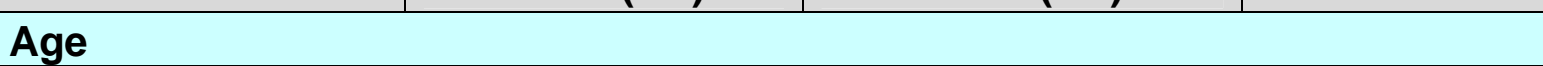 } \\
\hline & $34.7(9.4)$ & 34.1 (10.1) & $34.4(9.7)$ \\
\hline & 19-59 (range) & 19-63 (range) & 19-63 (range) \\
\hline & $n(\%)$ & $n(\%)$ & Total \\
\hline \multicolumn{4}{|l|}{ Gender } \\
\hline Male & $24(48.0 \%)$ & $27(48.2 \%)$ & 51 (48.1\%) \\
\hline Female & $26(52.0 \%)$ & $29(51.8 \%)$ & 55 (51.9\%) \\
\hline \multicolumn{4}{|l|}{ Race } \\
\hline African-American & $24(48.0 \%)$ & $26(46.4 \%)$ & $47(47.2 \%)$ \\
\hline Caucasian & $24(48.0 \%)$ & $28(50.0 \%)$ & 52 (49.1\%) \\
\hline Hispanic & $1(2.0 \%)$ & $1(1.8 \%)$ & $2(1.9 \%)$ \\
\hline Native American & $1(2.0 \%)$ & $1(1.8 \%)$ & $2(1.9 \%)$ \\
\hline \multicolumn{4}{|l|}{ HIV Status } \\
\hline Positive & $13(26.0 \%)$ & $15(26.8 \%)$ & $28(26.4 \%)$ \\
\hline Negative & 37 (74.0\%) & 41 (73.2\%) & 78 (73.6\%) \\
\hline
\end{tabular}

Note: None of the between group differences were significant at p 05 . 


\section{Hypothesis Testing}

Hypothesis 1: Subjects in the treatment group (IOP + up to $5 \mathrm{MI}$ sessions in the first two weeks) will attend significantly more IOP sessions than those in the comparison group.

An independent sample $t$-test was conducted to test Hypothesis 1 . In the total sample the mean number of days in treatment was $35(S D=30)$ with a range from 1 to 120 days (Figure 2). Forty-four subjects attended less than 20 days, a time in which most treatment dropout occurs (Anglin \& Hser, 1990).

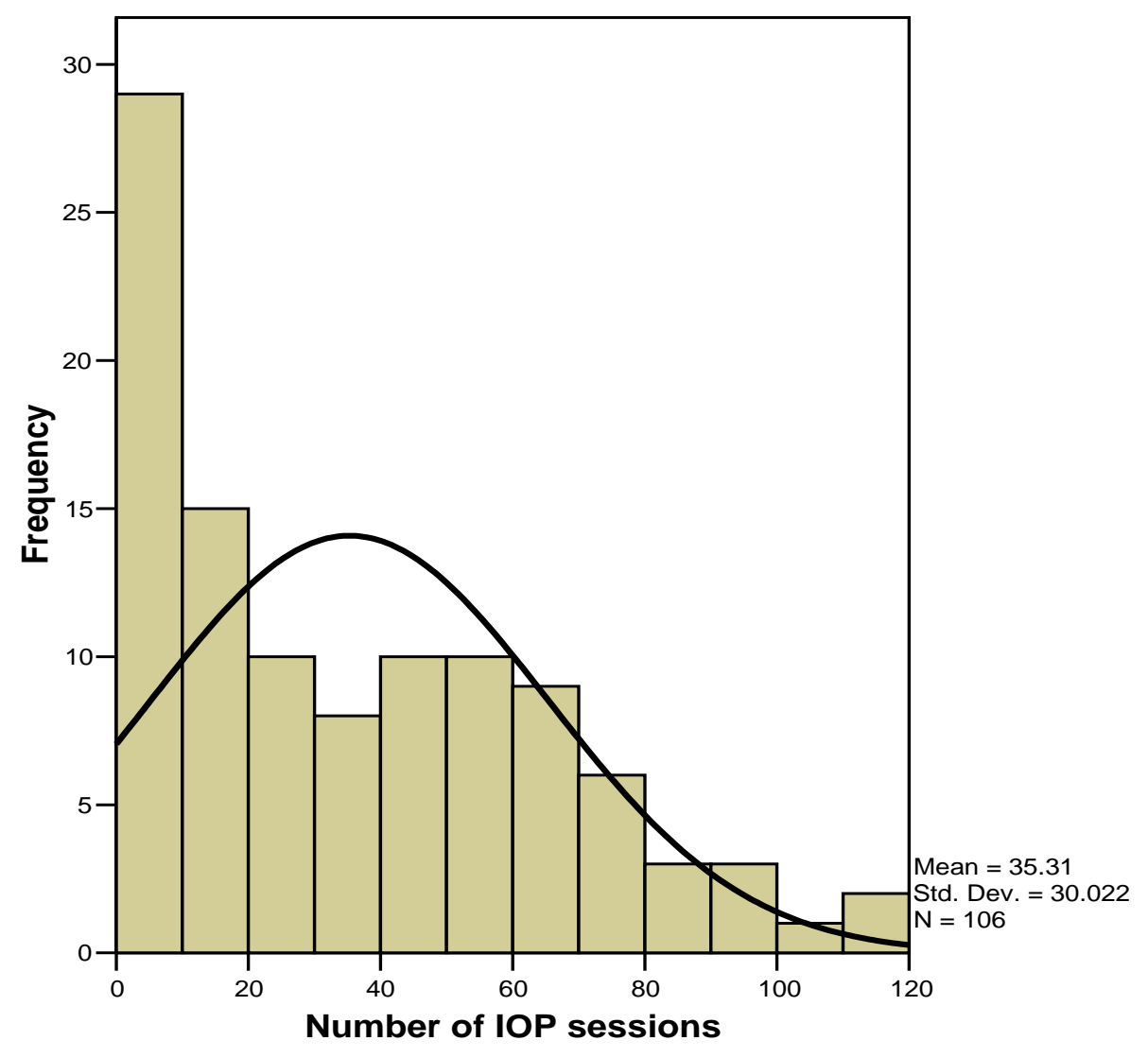

Figure 2. Histogram of attendance for total sample. 
Figure 3 is a histogram of attendance in days for the treatment group. The mean number of days attended for the treatment group spent was $33(S D=27)$ days. The distribution is positively skewed with half of the subjects in the treatment group dropping out within the first 20 days of treatment

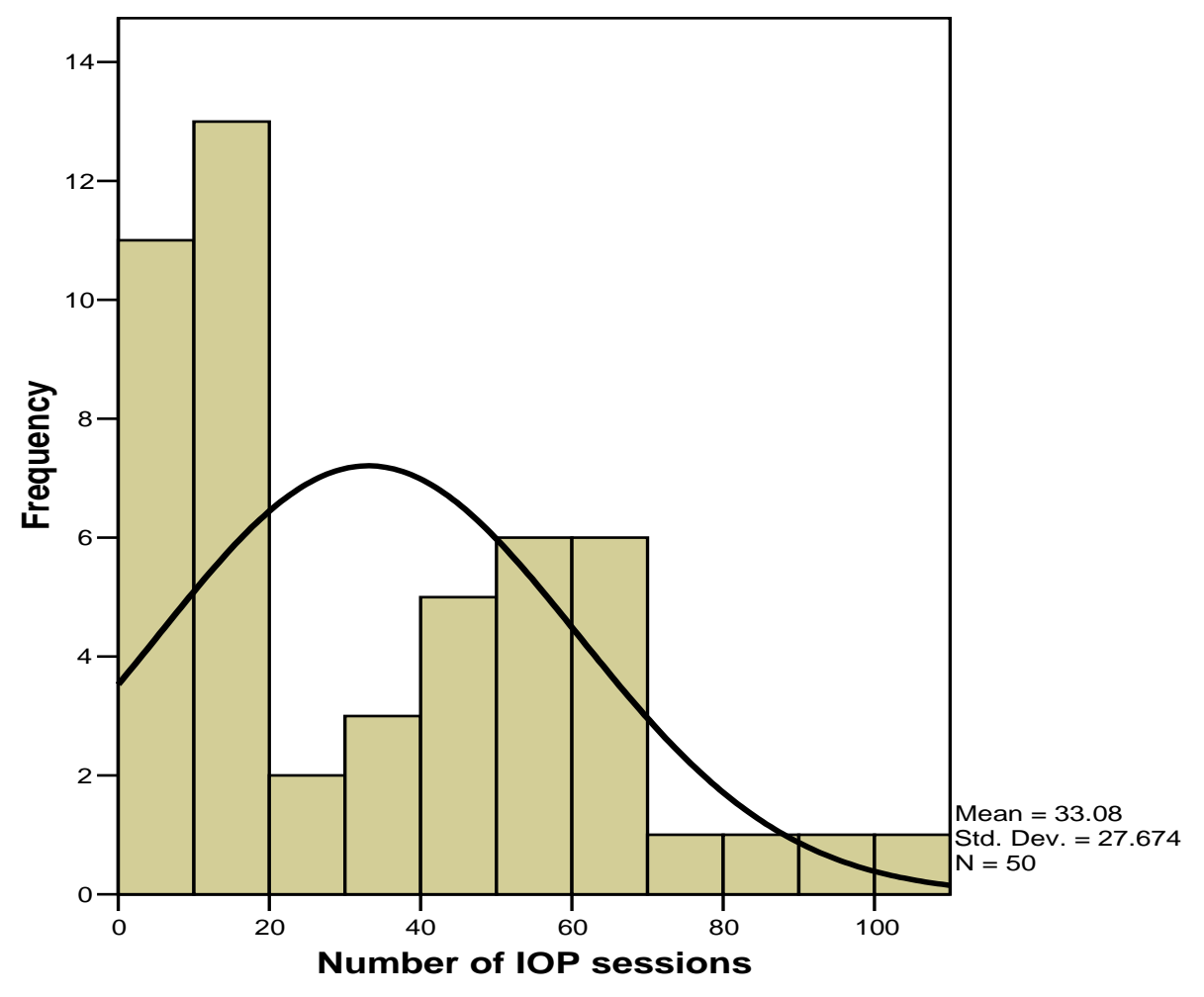

Figure 3. Histogram of attendance for treatment group.

Figure 4 is a histogram representing the comparison groups' number of days in treatment. The comparison group had an average of 37 days in treatment $(S D=32)$. While positively skewed this distribution depicts a large proportion of people who dropped out within the first 20 days, and then a more normally distributed group of individuals who remained beyond 20 days. 


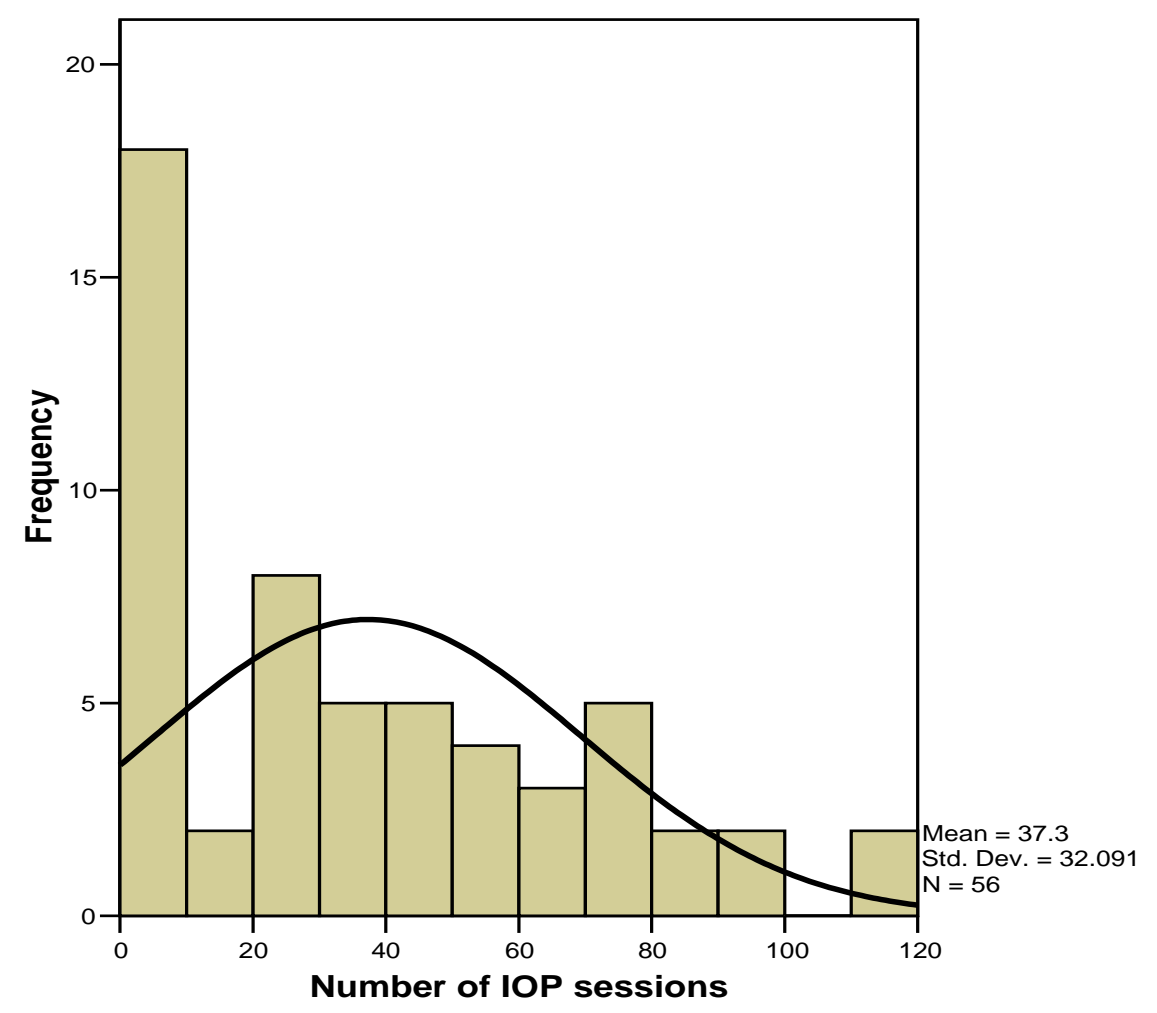

Figure 4. Histogram of attendance for the comparison group.

Table 4 reports the sample's mean number of days in treatment for both conditions and the total sample. The results of the 2-tailed $t$-test indicated that there was no significant difference between the mean number of days in treatment between groups $(t=.721, d f=104, p=.472, n=106)$. Therefore, $\mathrm{H}_{1}$, that subjects in the IOP program who were assigned to the treatment group would have increased retention as measured by days in treatment, is rejected. A power analysis with $t$-test yielded a medium effect size (0.5) (alpha $=0.05$; delta $=2.5698$; critical $t(104)=1.6596 ;$ power $=0.8181)$. While not statistically significant, the means varied in the opposite direction of what was hypothesized, with the comparison group remaining in the program longer than the treatment 
group (mean of 37.3 days for the comparison group compared to 33 days for the treatment group, Table 4).

Table 4

Number of Days in Treatment

\begin{tabular}{|l|c|c|c|}
\hline & Treatment $(\boldsymbol{n}=\mathbf{5 0})$ & Comparison $(\boldsymbol{n}=\mathbf{5 6})$ & Total $(\boldsymbol{n}=\mathbf{1 0 6})$ \\
\hline Mean (SD) & $33(27)$ & $37.3(32)$ & $35.3(30)$ \\
\hline
\end{tabular}

Hypothesis 2: A higher percentage of AOD addicted subjects in the treatment group (IOP + up to $\mathbf{5}$ added on MI sessions in the first two weeks) will complete treatment than those in the comparison group.

Overall, 75 of the subjects (70.8\%) dropped out of the program before completing, including $72 \%$ of the comparison group and $69 \%$ of the treatment groups. Inversely, only $28 \%$ and slightly more than $30 \%$, of the comparison and treatment groups, respectively, completed treatment (Table 5). Chi-square tests indicate that the intervention did not play a significant role in treatment completion (chi-Square $=.082, d f=1, p .774, n=106$ ) resulting in the rejection of the hypothesis. The results are in the opposite direction of the hypothesis. The power for $f$-test on Means is low, ANOVA with medium effect size $(0.25)$ (alpha $=$ $0.05 ;$ power $=0.7224 ;$ critical $\mathrm{F}(1,104)=3.9324 ;$ Lambda $=6.625 ;$ Table 5).

\section{Retention and Completion by HIV Status}

As stated earlier, part of the overall purpose of the study was to test the intervention on a sample representative of the treatment program, as well as 


\section{Table 5}

Dropout and Completion by Treatment and Comparison Groups

\begin{tabular}{|l|c|c|c|}
\hline & Treatment & Comparison & \multicolumn{1}{c|}{ Total } \\
\hline \% Dropout & $34(69.4 \%)$ & $41(71.9 \%)$ & $75(70.8 \%)$ \\
\hline \% Completed & $15(30.6 \%)$ & $16(28.1 \%)$ & $31(29.2 \%)$ \\
\hline Total & $49(100.0 \%)$ & $57(100.0 \%)$ & $106(100.0 \%)$ \\
\hline
\end{tabular}

Chi-Square $=.082, d f=1, p .774$

those who were HIV-infected. This is consistent with Rounsaville, Carroll, and Onken's (2001) methods of intervention development that contend that small samples ( $n=30$ to 60 ) Stage $1 b^{1}$ pilot studies are necessary as an initial step in intervention development even though statistical power is admittedly limited.

\section{HIVIAIDS Sample Description}

Table 6 reports demographics of subjects self-identifying as being HIVinfected and entering into the IOP clinic-only those who self-identified in this manner are included in this section. Thirteen HIVIAIDS subjects were assigned to the treatment group, and 15 to the comparison group. On average, subjects in this HIVIAIDS sub-sample of 28 were approximately 37 years of age $(S D=9.1)$. The majority of the HIVIAIDS subjects were men $(n=19,67.9 \%)$. The total HIVinfected sample was disproportionately made up of minorities; approximately $71 \%$ of subjects in this sub-sample were African American and $28 \%$ were White. Nine of the total 19 males in the HIVIAIDS sub-sample were assigned to

$1 \quad$ Stage 1a: Therapy Development \& Manual Writing

Stage 1b: Pilot trials

Stage 2: Full-scale randomized clinical trials 
Table 6

Baseline Characteristics of HIVIAIDS Positive Respondents

\begin{tabular}{|l|c|c|c|}
\hline & $\begin{array}{c}\text { Treatment }(\boldsymbol{n}=13) \\
\text { Mean (SD) }\end{array}$ & $\begin{array}{c}\text { Comparison }(\boldsymbol{n}=15) \\
\text { M(SD) }\end{array}$ & Total $(\boldsymbol{n}=\mathbf{2 8})$ \\
\hline Age & $38.3(9.6)$ & $35.3(8.6)$ & $36.7(9.1)$ \\
\hline \multicolumn{5}{|c|}{} & $10(66.7 \%)$ & $19(67.9 \%)$ \\
\hline Gender & $9(69.2 \%)$ & $5(33.3 \%)$ & $9(32.1 \%)$ \\
\hline Male & $4(30.8 \%)$ & & \\
\hline Female & \multicolumn{3}{|c|}{} \\
\hline \multicolumn{5}{|c|}{ Race } & $12(80.0 \%)$ & $20(71.4 \%)$ \\
\hline African-American & $8(61.5 \%)$ & $3(20.0 \%)$ & $8(28.6 \%)$ \\
\hline Caucasian & $5(38.5 \%)$ &
\end{tabular}

Note: None of the between group differences were significant at the $p .05$ level

the treatment group. The racial mix in the two groups was similarly distributed. None of the between group differences were significant, suggesting that the groups were comparable.

\section{HIVIAIDS Status and Hypothesis 1 (Days in Treatment)}

There is no significant difference between the treatment and comparison groups in the mean number of days in treatment of those who were HIVIAIDS positive. However, setting aside the treatment and comparison groups, nonHIVIAIDS subjects have a significantly higher mean number of days in treatment than HIVIAIDS positive clients $(t=3.022, d f=104, p=.003, n=106)$. Figure 5 shows the mean number of days in IOP care by treatment/comparison group and HIVIAIDS status/non. Figure 5 shows that AOD clients who are HIVIAIDS negative are in treatment the longest, 43 days for the comparison group and 37 days for the treatment group (first two bars in Figure 5). 


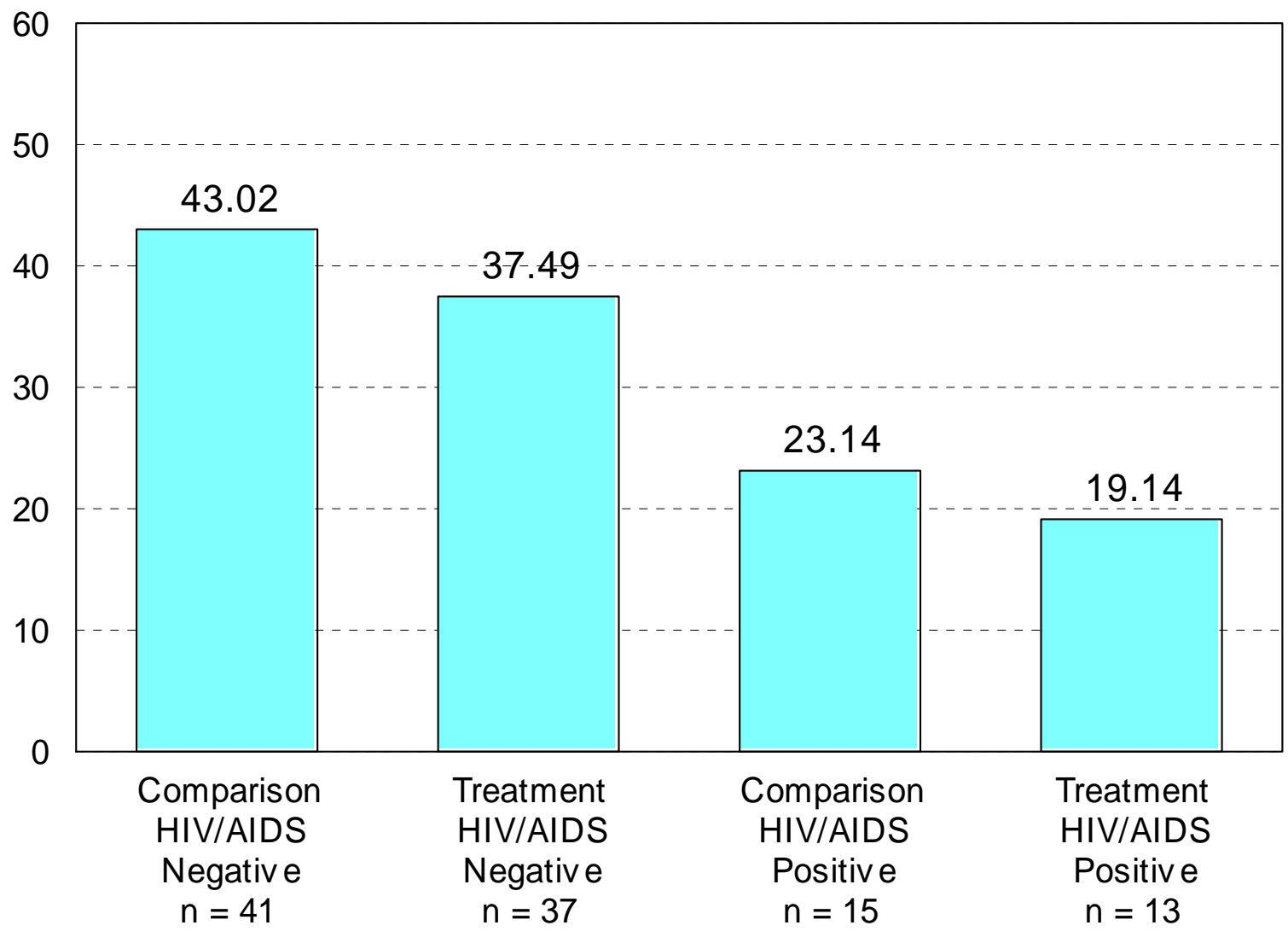

Figure 5. Mean number of days in treatment by group and HIVIAIDS status $(p$.024)

\section{HIVIAIDS Status and Hypothesis 2 (Treatment Completion)}

Of the 28 HIVIAIDS positive subjects, five (18\%) completed treatment, 2 in the treatment group and 3 in the comparison group (chi-Square $=2.385, d f=$ $1, p=.123, n=28)$. Due to the low number of HIV-infected subjects entering the program, data analysis was limited. Analyzing the effects of the MI booster sessions attended on completing treatment using cross tabulation resulted in too many cells with expected frequencies less than five, thereby not generating a valid statistical result. However, the counts and percentages are in Table 7. 


\section{Table 7}

\section{Treatment Completion by HIVIAIDS Status}

\begin{tabular}{|c|r|r|r|r|r|r|}
\hline & \multicolumn{2}{|c|}{ Treatment } & \multicolumn{2}{c|}{ Comparison } & \multicolumn{2}{c|}{ Total } \\
\hline Dropped Out & 11 & $84.6 \%$ & 12 & $80.0 \%$ & 23 & $82.1 \%$ \\
\hline Completed & 2 & $15.4 \%$ & 3 & $20.0 \%$ & 5 & $17.9 \%$ \\
\hline Total & 13 & $100.0 \%$ & 15 & $100.0 \%$ & 28 & $100.0 \%$ \\
\hline
\end{tabular}

\section{Supplemental Analyses}

Three additional supplemental analyses were conducted to attempt to explain the results of the study. In these analyses, only the number of IOP sessions dependent variable was used, since completion status is a function of the number of IOP sessions attended. In other words, number of days in treatment dictates completion, making it a circular exercise, or redundant.

The first supplemental analysis was conducted to investigate the influence of 10 subjects in the treatment condition (who included to satisfy an intent to treat test, in bold in Table 8), and who received no MI sessions on the outcome, the number of IOP sessions. ${ }^{2}$ Table 8 shows the mean, median, mode and standard deviation of MI sessions provided to the treatment group, along with frequency of sessions attended.

The median number of sessions received by those in the treatment group $(n=50)$ was 2 . In order to control for the possible effect of not attending any MI sessions, the 10 subjects who received no MI sessions were excluded from the treatment group in this analysis only. Table 9 shows the descriptive statistics for

Ten subjects assigned to the treatment condition left treatment prior to meeting with the $\mathrm{MI}$ counselor, thus they received no MI sessions. As stated earlier, these subjects were included in the original analysis of both hypotheses. 
Table 8

Number and Frequencies of Motivational Interviewing Sessions

\begin{tabular}{|c|c|c|c|}
\hline Mean & Median & Mode & $\begin{array}{c}\text { Standard } \\
\text { Deviation }\end{array}$ \\
\hline 2.1 & 2 & 3 & 1.5 \\
\hline & & & \\
\hline Motivational Interviewing Sessions & Frequency & $\%$ & \\
\hline 0 & 10 & 20 & \\
\hline 1 & 9 & 18 & \\
\hline 2 & 9 & 18 & \\
\hline 3 & 12 & 24 & \\
\hline 4 & 8 & 16 & \\
\hline 5 & 2 & 4 & \\
\hline
\end{tabular}

Table 9

Descriptive Statistics of Total Sample and After Exclusion

\begin{tabular}{|c|c|c|c|c|c|c|c|c|c|}
\hline Sample Variables & \multicolumn{2}{|r|}{$\mathbf{N}$} & \multicolumn{3}{|c|}{$\begin{array}{c}\text { Mean } \\
\text { Percentage }\end{array}$} & Mode & Range & \multicolumn{2}{|c|}{$\begin{array}{l}\text { Standard } \\
\text { Deviation }\end{array}$} \\
\hline \multicolumn{10}{|l|}{ Age at Admission } \\
\hline Total Sample & & 106 & \multicolumn{3}{|c|}{34.4} & 28 & $19-63$ & & 9.7 \\
\hline Treatment & & 50 & \multicolumn{3}{|c|}{34.7} & 19 & $19-59$ & & 9.4 \\
\hline Comparison & & 56 & \multicolumn{3}{|c|}{34.1} & 41 & $19-63$ & \multicolumn{2}{|r|}{10.1} \\
\hline $\begin{array}{r}\text { Treatment after } \\
\text { Exclusion }\end{array}$ & & 40 & \multicolumn{3}{|c|}{34.6} & 19 & $19-59$ & \multicolumn{2}{|r|}{9.5} \\
\hline \multicolumn{3}{|l|}{ Gender } & \multicolumn{4}{|c|}{ Female } & \multicolumn{3}{|c|}{ Male } \\
\hline & \multicolumn{2}{|c|}{ Total Sample } & \multicolumn{2}{|c|}{\begin{tabular}{l|l}
55 &
\end{tabular}} & \multicolumn{2}{|c|}{$51.9 \%$} & 51 & \multicolumn{2}{|c|}{$48.1 \%$} \\
\hline & \multicolumn{2}{|c|}{ Treatment } & \multicolumn{2}{|c|}{26} & \multicolumn{2}{|c|}{$52.0 \%$} & 24 & \multicolumn{2}{|c|}{$48.0 \%$} \\
\hline & \multicolumn{2}{|c|}{ Comparison } & \multicolumn{2}{|c|}{29} & \multicolumn{2}{|c|}{$51.8 \%$} & 27 & \multicolumn{2}{|c|}{$48.2 \%$} \\
\hline \multicolumn{3}{|c|}{ Treatment after Exclusion } & \multicolumn{2}{|c|}{19} & \multicolumn{2}{|c|}{$47.5 \%$} & 21 & \multicolumn{2}{|c|}{$52.5 \%$} \\
\hline Race & \multicolumn{2}{|c|}{ Black } & \multicolumn{3}{|c|}{ White } & \multicolumn{2}{|c|}{$\mathrm{NAI}^{3}$} & \multicolumn{2}{|c|}{ Hispanic } \\
\hline Total Sample & 47 & $47.2 \%$ & 52 & 49. & & 2 & $1.9 \%$ & 2 & $1.9 \%$ \\
\hline Treatment & 24 & $48.0 \%$ & 24 & 48. & & 1 & $2.0 \%$ & 1 & $2.0 \%$ \\
\hline Comparison & 26 & $46.4 \%$ & 28 & 50. & & 1 & $1.8 \%$ & 1 & $1.8 \%$ \\
\hline $\begin{array}{r}\text { Treatment after } \\
\text { Exclusion }\end{array}$ & 20 & $50.0 \%$ & 18 & $45 .($ & & 1 & $2.5 \%$ & 1 & $2.5 \%$ \\
\hline \multicolumn{3}{|l|}{ HIVIAIDS Status } & & Neg & IV & & & sitive & \\
\hline & $\overline{\text { Tota }}$ & Sample & & 78 & & $3.6 \%$ & 28 & & $.4 \%$ \\
\hline & & eatment & & 37 & & $4.0 \%$ & 13 & & $.0 \%$ \\
\hline & Cor & iparison & & 41 & & $3.2 \%$ & 15 & & $.8 \%$ \\
\hline Treatment af & Ex & Iusion & & 28 & & $0.0 \%$ & 12 & & $.0 \%$ \\
\hline
\end{tabular}

$3 \quad$ Native American Indian 
the truncated treatment group (data for the full treatment group are also presented for comparison purposes) and the comparison group.

Results of a $t$-test indicated that there was no significant difference between the truncated treatment and comparison groups in mean number of IOP sessions attended $(t=.178, d f, 94, p=.859)$. Thus the inclusion or exclusion of the 10 subjects in the treatment group who received no $\mathrm{Ml}$ sessions did not significantly influence the number of IOP sessions attended.

A second supplemental analysis included both univariate and multivariate analyses to better understand the differences and similarities in the correlates and predictors of the number of IOP sessions attended. First, correlations among demographic variables, independent variables, additional measures, and dependent variables (Table 2) were analyzed. Variables that were significantly related to the primary outcome, number of IOP sessions attended, were retained for inclusion in the multivariate analyses. A multiple regression was conducted to identify those variables that accounted for a significant proportion of the variance in the outcome. In the first block, any variable, with the exception of the primary independent variable (treatment vs. comparison group), that was found to be significantly related to the outcome in the bivariate analysis was entered. In the second block, the treatment condition was entered. Table 10 presents the correlation matrix of age, gender, race, HIVIAIDS status, number of MI sessions, number of IOP sessions, completion, MI dose, and client severity. 
Examination of Table 10 indicates that two variables were significantly related to the outcome (number of IOP sessions): HIVIAIDS status and client severity. While the relationship between number of MI sessions and number of IOP sessions did not reach the conventional level of significance, it was approaching significance $(p=.065)$.

\section{Table 10}

\section{Correlation Matrix}

\begin{tabular}{|c|c|c|c|c|c|c|c|c|c|}
\hline & 1 & 2 & 3 & 4 & 5 & 6 & 7 & 8 & 9 \\
\hline 1. Age & & .074 & .087 & -.016 & -.011 & .005 & .031 & .043 & -.135 \\
\hline 2. Gender & .074 & & -.065 & $\star_{-} .237$ & .145 & -.066 & .079 & .206 & $\star .204$ \\
\hline 3. Race & .087 & -.065 & & $\star^{* *}-.286$ & .277 & .221 & -.004 & *.332 & .131 \\
\hline \begin{tabular}{|l|} 
4. HIV \\
Status
\end{tabular} & -.016 & $\begin{array}{r}- \\
* .237\end{array}$ & $\star^{* *}-.286$ & & -.040 & $\star^{* *}-.284$ & -.150 & -.066 & -.091 \\
\hline $\begin{array}{l}\text { 5. \# of Ml } \\
\text { sessions }\end{array}$ & -.011 & .145 & .277 & -.040 & & .263 & .103 & $\star \star .862$ & .085 \\
\hline $\begin{array}{r}\text { 6. \# of IOP } \\
\text { sessions }\end{array}$ & .005 & -.066 & $\star .221$ & $*_{-} .284$ & .263 & & $\star \star .633$ & .122 & $\star \star .453$ \\
\hline 7. Completion & .031 & .079 & -.004 & -.150 & .103 & $\star \star 633$ & & -.053 & $\star * .258$ \\
\hline 8. MI Dose & .043 & .206 & *.332 & -.066 & **.862 & .122 & -.053 & & .020 \\
\hline $\begin{array}{l}\text { 9. } \text { Client } \\
\text { Severity }\end{array}$ & -.135 & *.204 & .131 & -.091 & .085 & **.453 & $\star \star 258$ & .020 & \\
\hline
\end{tabular}

Pearson's correlations: * $=$ Significant at $p \leq .05$; ${ }^{*}$ Significant at $p \leq .01$ (2-tailed).

Three variables were retained for inclusion in the multivariate model: HIVIAIDS status, client severity, and number of MI sessions attended. Although the number of MI sessions failed to yield a significant relationship with the primary outcome, it was retained in the multivariate analysis because it approached significance and was a major component of both hypotheses. Table 11 shows the unstandardized regression coefficients (b), standard errors (SE), and standardized beta for the regression model. The linear combination of 
variables in the multivariate model accounted for $32 \%$ of the variance in the number of IOP sessions attended. Examination of Table 12 indicates that client severity and HIV status were significant predictors of the number of IOP sessions attended. Given the findings in the bivariate analysis, it was not surprising that the number of $\mathrm{Ml}$ sessions attended was not a significant predictor of the outcome, number of IOP sessions attended.

The fact that the $2^{\text {nd }}$ block is not significant indicates that the severity and HIVIAIDS status were significant at predicting number of IOP sessions $\left(r^{2}\right.$ change $=.315, f=10.801, d f=47, p,=.000)$. However, even when controlling for effects of severity and HIVIAIDS status, MI group involvement was not significant at predicting number IOP sessions $\left(r^{2}\right.$ change $\left.=.042, f=3.042, d f=46, p .=.088\right)$

Table 11

Unstandardized Regression Coefficients

\begin{tabular}{|l|c|c|}
\hline \multicolumn{3}{|c|}{ Dependant Variable $=$ Number of IOP Sessions Attended } \\
\hline \multicolumn{3}{|c|}{ Model 1 } \\
\hline Variable & Beta Coefficient & Std. Error \\
\hline Client Severity & $27.995^{\star \star}$ & 6.882 \\
\hline HIV Status & $-24.107^{\star \star}$ & 7.743 \\
\hline \multicolumn{3}{|c|}{} \\
\hline Model 2 \\
\hline Variable (excluded) & Beta Coefficient & Std. Error \\
\hline MI Sessions & 3.819 & 2.19 \\
\hline
\end{tabular}

*Significant at $p \leq .05$; ** Significant at $p \leq .01$. 
Table 12

Relationship between HIVIAIDS \& Client Severity

\begin{tabular}{|l|c|c|r|}
\hline & HIVIAIDS Negative & HIVIAIDS Positive & \multicolumn{1}{l|}{ Total } \\
\hline Severe & $31(39.7 \%)$ & $14(50.0 \%)$ & $45(42.5 \%)$ \\
\hline Not Severe & $47(60.3 \%)$ & $14(50.0 \%)$ & $61(57.5 \%)$ \\
\hline Total & $78(100.0 \%)$ & $28(100.0 \%)$ & $106(100.0 \%)$ \\
\hline
\end{tabular}

The third and final supplemental analysis was a chi-square testing the relationship between HIVIAIDS status and client severity (Table 12). This analysis was done to determine if the most severe clients were those who were HIVIAIDS positive. Overall, 45 of the subjects (42.5\%) were severe, including $39.7 \%$ of the HIVIAIDS negative and 50\% HIVIAIDS positive. Those subjects not severe totaled 61 (57.5\%) with 60.3\% HIVIAIDS negative and 50\% HIVIAIDS positive. This final supplemental analysis resulted in a non-significant relationship (chi-square $=.887, d f=1, p .379, n=106)$.

\section{Summary of Results}

Neither of the two hypotheses were supported. Contrary to the MI literature, an average of two $\mathrm{Ml}$ booster sessions did not result in subjects in the treatment group attending more IOP sessions or completing treatment for addiction to alcohol and other drugs. Supplemental analyses, however, showed a statistically significant relationship between HIVIAIDS status, severity (or the degree to which clients appeared to be sufficiently stable to be located for followup assessments), and days in IOP treatment: HIVIAIDS positive clients perceived as high in severity were more likely to drop out of treatment. 


\section{CHAPTER V}

\section{DISCUSSION AND IMPLICATIONS}

The results of this study suggest that additional Motivational Interviewing sessions within the first two weeks of treatment do not increase the number of days in intensive outpatient treatment for VOA's clients addicted to alcohol and other drugs, some of whom are also HIVIAIDS positive. Neither is there a statistically significant relationship between having/not having additional Motivational Interviewing sessions in the first two weeks of treatment and completing treatment. The first reaction to this news is to search for flaws in the research design, and the most prominent error was this designer's misunderstanding of the exact nature of clients' problems. For example, this researcher underestimated the magnitude of the impact of myriad negative factors in clients' histories, relationships, and social environments that have resulted in their current predicaments: addicted to alcohol and other drugs, and in $26 \%$ of the sample, positive for HIVIAIDS. In hindsight, how could a few motivational sessions overcome lifetimes of negative influences?

\section{Implications of Theoretical Perspectives}

This final chapter begins with examining the implications of this study relating to the theoretical perspectives that provided guidance. Some 
weaknesses and oversights will be discussed along with study design flaws. It concludes with knowledge gained and recommendations for future research.

Looking back at the theoretical perspectives of Rogers and Prochaska and how those perspectives informed and guided this study, is important for the future direction of researching this specific population. From Rogers' perspective we are born with a positive valuing process that enhances and maintains those positive things in our lives, and devalue negative experiences that stagnate our growth potential. Rogers $(1951,1961, \& 1980)$ concluded that our worlds are of our own making (our reality) and that in order for someone else to understand our real realities they must attempt to place themselves in our frames of reference. Once we can truly understand ourselves, we seek positive regard for that self.

Rogers' (1951, 1961, \& 1980) goal in treatment is basically what should happen during treatment. The therapist should be empathic always with an eye toward valuing the client. As stated earlier, this provides a venue and justification for intervening with the Motivational Interviewing approach. Successfully applying MI during a counseling session is to be empathic with the client, or as Miller and Rollick (2002) claim, MI is a way of being with people.

Focusing on what happens during the therapy process is vital. However, what was discounted during this study (as well as Rogers' theoretical underpinning $[1951,1961, \& 1980])$ was the limited resources the client brings to therapy sessions. This theoretical perspective assumes that the client has sound personal agency outside of the therapeutic arena, and that the identified problem 
at hand can be the main focus during its treatment. Unfortunately, for many individuals entering into treatment, the power of during treatment therapeutic empathy cannot revise the rule of 24/7 poverty. Can a therapist meet the level of being empathic while working under the assumption that the lack of motivation or poor personal agency is the cause, and targeting it can be the cure?

\section{Methodological Limitations}

There was a departure from sequential random sampling. Because those who entered the program being addicted to alcohol and other drugs as well as suffering from HIVIAIDS made up a much smaller segment, one adjustment was made to better balance experimental and control groups. After several months of sequential assignment and close to the end of the study, a decision was made to place the next HIVIAIDS subject into the comparison group in order to balance out the two groups. This adjustment violated assumptions of random sampling. Another limitation was not monitoring the intervention for fidelity. While the MI counselor was well seasoned, trained, and credentialed, it is not known whether the proposed protocols were followed as none of the sessions were observed or taped.

The sample and statistical power are also small. However, Rounsaville et al. (2001) noted that small pilot studies of 15 to 30 subjects per group are necessary in Stage $1 \mathrm{~b}$ of intervention development research. The sample is a single site community of people receiving addiction treatment; therefore, the results cannot be generalized to other populations. 
Another study limitation was not obtaining baseline data related to possible factors which were contrary to treating addiction at the most minimum level of care--outpatient. Although randomization would seemingly have solved baseline differences, it cannot be assumed that clients living in poverty are outliers and would be equally distributed. The majority of subjects in the study could have enormous external forces working against remaining in minimal care. This could explain the $70 \%$ termination from treatment before completion. To think that a few empathic Motivational Interviewing sessions during the first two weeks of IOP treatment could overpower the awesome forces this population deals with on a daily basis was blatant naivety.

Based on working in the Volunteers of America system for about 10 years, it is clear that the most common characteristic of VOA clients is that they live in poverty which is commonly overlooked and misunderstood. In addition, a majority of clients entering this VOA program do not have stable living arrangements or even the most basic necessities. They have histories of chronic medical dilemmas (e.g. diabetes, HIVIAIDS, Tuberculosis, and Hepatitis) along with the lack any health care services. While they may live within walking distance of some of the best health care facilities in the world, they are denied that care because they have no jobs and little/no income or insurance. They also present with multiple addictions beginning early in life and developing into chronic conditions that are much more difficult to treat. Involvement in the criminal justice system is something that is simply expected. Due to the intergenerational effects of poverty, this population is also deficient in any social or family support 
stemming from the intergenerational effects of poverty. Having entered into addiction treatment services, all of those co-evolving problems continue without regard to the best intentions of the empathic Motivational Interviewing therapist.

The individual suffering from these problems could be considered to be pauper type addicts. This is not an attempt to coin a clever label, but a suggestion for a new way of thinking and treating a unique person who requires specific services. Many times this cohort is labeled as homeless. But that does not get to the marrow of what is occurring in their lives. The homeless identity also sends a message to the professional helper about which problem to deal with first. The pauper type addict's assessed problems cannot be hierarchically ranked and dealt with one at a time. Their problems are like Aspens, where people like to vacation - the trees bloom together because they are connected by their roots. So must the problems of such clients be addressed togetherbecause they are connected by their roots.

This study was guided by the Transtheoretical Stages of Change model (Prochaska \& DiClemente, 1983, 1984). Unfortunately, when treating the pauper type addict for addiction, this model seems to also overlook the unique, coevolving problems of the sufferer. The stages-of-change-model consists of how and why people change on their own as well as with some type of professional assistance. The model describes a set of predictable stages through which people travel in the course of altering addicted behavior: Preconception, Contemplation, Determination, Action, and Maintenance. The groundwork for this model came from working with tobacco addictions and expanded to other 
behavioral problems. Working within the stages of change framework seems to require the dedicated attention toward that central, one and only, specifically identified problem. As a specific problem is addressed, the individual, along with the therapist, monitors that particular stage of change in order to adequately adjust the therapeutic intervention.

The goal is to move through the stages as smoothly as possible. There is an acceptance that while working on that problem one could move both backward and forward through the stages. So the individual and therapist have one problem and five different stages to monitor. The pauper type addict could have up to five equally serious problems to address (i.e. housing, employment, addiction, medical, and criminal justice). This would require monitoring five coevolving problems with five different fluid stages. Because each individual problem is influenced and connected to every other problem (e.g. obtaining adequate housing would require being able to pay rent, which would also require employment, resulting in limiting the time it takes to treat addiction), monitoring the stages of change and intervening appropriately would be almost impossible. The therapist would have to keep track of five specific and connected problems with five different stages for each problem, resulting in at least 25 possible intervention opportunities that are constantly evolving and moving in every direction (easier said than done!).

Smoking is a straightforward problem to deal with using the stages of change model. It is one problem that can take a back seat when a more serious problem arises. Usually it does not require entering into a treatment facility for 
several hours weekly and lasting several weeks or even months. Treating the problem of smoking can also be postponed or even discouraged if a more serious problem occurs. Smoking clients are normally not under the pressures of going to jail, losing their jobs, being evicted or even losing custody of their children for discontinuing the smoking treatment due to a more serious issue arising in their lives. It is a matter of prioritizing problems.

This is not the case with addicts or pauper type addicts who are involved in addiction treatment. If they postpone or discontinue addiction treatment, serious consequence may ensue. While there could be more serious problems arising in the life of pauper type addicts during addiction treatment services, if they drop out of those services, it is usually seen as a lack of motivation, or in other words, the client is held responsible by being described as noncompliant.

While the stages of change seemed to be an appropriate framework, it may be limiting when dealing with an addicted population with multiple problems requiring an array of change stages to monitor. And while Motivational Interviewing and the stages of change may rely too heavy on client personal agency (an internal motivational flaw), lacking regard for any other external forces at work.

\section{Research Inclusion and Exclusion Activities}

Having re-examined the MI literature to provide more background for the intervention, many studies have specific inclusion/exclusion criteria. For example, Project MATCH excluded those who were homeless and involved in the criminal justice system. A randomized trial in drug abuse services conducted by Miller 
and Rollnick (2002) provided Motivational Interviewing sessions to patients in order to elicit behavior change by exploring and resolving ambivalence. They enrolled 152 outpatient and 56 inpatient clients who were entering a public agency for drug problems. The researchers reported and excluded clients if they reported insufficient residential stability.

This is not an attempt to take away from the credibility of Motivational Interviewing or any Motivational Interviewing research. It seems to work very well with specific groups in specific environments. Future interventions must include every client entering the facility under study (within the parameters of informed consent) or they will not represent real world clinical activities.

After realizing the weakness of not collecting any baseline data, an effort was made to obtain information about subjects' treatment histories. Because the VOA outpatient clinic is funded by SAMSHA-CSAT it is required to treat a specific number of clients. SAMSHA-CSAT mandates treatment programs to gather baseline data on clients who enter these programs and enter these data into SAMSHA-CSAT's on-line data system, Government Performance and Results Act (GPRA). Once a program enters the client's baseline data into the system, SAMSHA-CSAT mandates 6 and 12-month followup with these clients. If programs are unable to obtain an $80 \%$ followup rate for six and 12 months, the program could lose funding. It is recommended that in order to obtain the $80 \%$ follow up rate, programs must be careful when deciding who they enter into the GPRA system. If a client presents as difficult to follow up (e.g., unstable living arrangements or homeless, pending legal charges, and/or recent move from out 
of state) the program may provide treatment, but not enter this hard to followup client into the GPRA.

Of the 106 subjects entering this study, 45 (42.5\%) were evaluated to be hard to followup clients and not entered into the GPRA database. While they were accepted into IOP treatment, the pressure of locating them at 6 and 12 months was relieved. This practice is not uncommon in research designs, in order for research results to be accepted, a specific follow rate is mandated. However, the only significant finding resulting from this study was between those subjects who were evaluated as hard to follow compared to those subjects evaluated as appropriate to enter into the GPRA database and locating at 6 and 12 months.

Those subjects entered into the GPRA (those evaluated as being stable enough to find at 6 and 12 months) remained in IOP treatment significantly longer than those subjects who were evaluated as hard to follow up $(t=-5.180$, $p .=.000)$. The relationship between treatment completion and being entered into the GPRA database was also significant. A higher percentage of clients not entered into the GPRA (hard to follow) dropped out of treatment compared to those who were entered into the GPRA database (Chi-Square $=7.082, d f=1, p$ $.008)$.

These findings relate back to subject exclusion based on research requirements that demand specific followup rates. While subjects meeting research inclusion criteria and entered into studies produce higher followup rates 
and acceptable data analyses, the effects of research exclusion could have significant clinical effects on those excluded from research.

\section{Treatment as Usual}

The final implication is the idea of treatment as usual. This study did not speak extensively to the specific treatment being offered to subjects and how it relates to generalizable outcomes. An assumption of the current design was that everyone receiving treatment as usual served as a control for both groups. Never considered was the question of, what is usual treatment? Does treatment as usual mean the best evidence-based treatment being offered? The assumption made when using treatment as usual is that as long as both groups get it, treatment quality does not matter.

Treatment as usual without examining its quality, limits the study's generalizability, as well as the knowledge needed to inform best practices. For instance, if a study was designed to investigate the effects of medication on retention and completion within a tuberculosis clinic, treatment as usual would have to be the best, medically agreed upon activity. Let's agree that the standard practice for treating and curing tuberculosis consists of taking four antituberculosis drugs over the course of six months. This would be treatment as usual due to its empirically based results. It cures tuberculosis without regard to geographic, socio-economic, or basic human demographic differences. The only problem with the tuberculosis therapy is that the sufferers are dropping out of the treatment regimen. 
An investigation to understand tuberculosis treatment retention and completion would be a worthy cause. Treatment compliance would ensure the elimination of tuberculosis. If conducting a study in a tuberculosis clinic it must provide these four medications in order to be considered treatment as usual. However, let say that due to cost constraint and the inability to treat every case of tuberculosis, there is a clinic in town (the Volunteer Clinic) that treats those who suffer for tuberculosis who do not have the necessary health care coverage to be treated in local prestigious clinics. While this volunteer clinic provides those same medications, it cannot afford them in the correct dosage. The volunteer clinic provides lower doses of the standard medications resulting in the treatment lasting twice as long. Therefore, the six months of treatment now must take a year. And for that individual whose untreated tuberculosis has caused greater medical complications, receiving the minimum treatment dose over a longer period of time cannot be quality care. Could this volunteer clinic be considered and studied using treatment as usual? Could the retention and completion findings at the volunteer clinic be generalized to other tuberculosis clinics providing substandard care? Are there research ethics involved in this real world dilemma? (Not to worry, the Institutional Review Boards are concerned with protecting people from research—not clinical services.)

Knowledge building becomes limited without knowing specifically how treatment as usual is being used within the research design. Treatment as usual should also be evaluated and clarified for its effectiveness on the problem being studied before accepted as a controlled research condition. This study, while not 
taking these issues in account, cannot produce the knowledge for which it was searching.

\section{Future Research}

Future research should address the outside influences on subjects. For instance, relying only on an in-treatment intervention without addressing housing issues, unemployment, medical conditions, or other overpowering forces requiring the immediate attention of the client, would have a limiting effect on outcomes. This study could be replicated using a case manager working to stabilize outside issues thereby allowing the subject to focus on remaining in treatment and only treating addiction. A case manager could assist with limiting the pressures of outside issues pulling subjects away from the priorities of treatment.

The same would be true of the addicted HIV-infected population coming into treatment. However, following Rounsaville, Carroll, and Onken's (2001) Stage 1b Pilot Trial model for research when including those who are HIVinfected into addiction treatment would require a greater amount of time in a larger study. Because this population usually requires many levels of care as well as being hard to follow, enrolling them into research studies demanding rigorous followup could be difficult.

This study was able to adhere to some of the Stage 1b Pilot Trial's aims. Alcohol and other drug addicted HIVIAIDS positive subjects were retained long enough to receive the intervention. This study was also able to recruit sufficient numbers of the targeted population to deliver the intervention and analyze some 
data. However, one aim was to obtain a clinically significant outcome on at least one important domain, which did not occur.

The recommendation for future research with a larger sample of those who are alcohol and other drug addicted would also apply to those entering HIV-infected. Connecting this population with a case manager who understands both disease conditions and is able to operate within the community to bring together appropriate services is vital to any further research. 


\section{REFERENCES}

AA Web Site (n.d.). AA at a glance. Retrieved from http://www.alcoholicsanonymous.org/default/en about aa.cfm?pageid=1 on 5/20/2005.

Adamian, M. S., Golin, C. E., Shain, L. S., \& DeVellis, B. (2004). Brief motivational intervention to improve adherence to antiretroviral therapy: development and Qualitative pilot assessment of an intervention. AIDS patient care \& STDs, 18(4), 229-238.

American Psychiatric Association. (1994). Diagnostic and statistical manual of mental disorders: DSM-IV. Washington, D.C.: American Psychiatric Association.

Anglin, M. D., \& Hser, Y. I. (1990). Treatment of drug abuse. In M. Tonry \& J.Q. Wilson (Eds.), Drugs and crime (pp.393-460). Chicago: University of Chicago Press.

Ashworth, O. (2005). Methadone maintenance treatment as an effective harm minimization intervention. Mental Health Practice, 8(8), 24-27.

Avins, A. L., Woods, W. J., Lindan, C. P. et al.,(1994). HIV infection and risk behaviors among heterosexuals in alcohol treatment programs. JAMA 271(7), 515-518.

Bacon, O., Lum, P., Hahn, J., Evans, J., Davidson, P., Moss, A., \& Page-Shafer, K. (2006). Commercial sex work and risk of HIV infection among young 
drug injecting men who have sex with men in San Francisco. Sexually Transmitted Disease, 33(4), 228-234.

Baseman, J., Ross, M., \& Williams, M. (1999). Sale of sex for drugs and drugs for sex: an economic context of sexual risk behaviors for STDs. Sexually Transmitted Diseases, 26(8), 444-449.

Basso, M. R., \& Bornstein, R. A. (2000). Neurobehavioral consequences of substance abuse and HIV infection. Journal of Psychopharmacology, 14(3), 228-237.

Bawa, A.C. (2005). Science, power, and policy intersecting at the HIVIAIDS pandemic. Social Research, 72(3), 605-620.

Boscarino, J. A., Avins, A. L., Woods, W. J., Lindan, C. P., Hudes, E. S., \& Clark, W. (1995). Alcohol-related risk factors associated with HIV infection among patients entering alcoholism treatment: implications for prevention. Journal of Studies on Alcohol, 56, 642-653.

Brehm, S. S., \& Brehm, J. W. (1981). Psychological reactance: A theory of freedom and control. New York: Academic Press.

Burke, B. L., Arkowitz, H., \& Dunn, C. (2002). The efficacy of motivational interviewing and its adaptations: What we know so far. In W. R. Miller \& S. Rollnick (Eds.) Motivational interviewing: Preparing people to change $\left(2^{\text {nd }}\right.$ edition), (pp 217-250) New York: Guilford.

Cahalan, D. (1987). Understanding America's drinking problem. San Francisco: Jossey-Bass. 
Campbell, D., \& Stanley, J. (1963). Experimental and quasi-experimental designs for research. Chicago: Rand McNally.

Catania, J. A., Osmond, D., \& Stall, R. D. (2002). The continuing HIV epidemic among men who have sex with men. American Journal of Public Health 91(6), 907-914.

Celentano, D. D., Valleroy, L. A., Sifakis, F., Mackellar, D. A., Hyton, J., Thiede, H., McFarland, W., Shehan, D. A., Stoyanoff, S. R., Lalota, M., Kobin, B. A., Katz, M. H., \& Torian, L. (2006). Associations between substance use and sexual risk among very young men who have sex with men. Sexually Transmitted Diseases 33(4), 265-271.

Center for Substance Abuse Treatment. (2002) Substance abuse treatment for persons With HIVIAIDS. Treatment Improvement Protocol (TIP) Series 37 DHHS Publication No. (SMA) 00-3460. Washington DC: U.S. Government Printing Office, Order No. BKD343.

Centers for Disease Control and Prevention (CDC) Surveillance Report. (2002). Volume 14.

Centers for Disease Control and Prevention. (2004a). HIVIAIDS among women: Centers for Disease Control.

Centers for Disease Control and Prevention. (2004b). HIVIAIDS among Women (in The Body).Center for Disease Control and Prevention. (1993). Technical guidance on HIV counseling. Morbidity and Mortality Weekly Report, 42(RR-2), 11-17. 
Connors, G. J., \& Rychtarik, R. G. (1989). The Supreme Court VA/disease model case: Background and implications. Psychology of Addictive Behavior, 2, 101-107.

Daley, D. C., Salloum, I. M., Zuckoff, A., Kirisci, L., \& Thase, M. E. (1998). Increasing treatment adherence among outpatients with depression and cocaine dependence: A pilot study. American Journal of Psychiatry, 155, 1611-1613.

del Rio, C., (2005). AIDS: The second wave. Archives of Medical Research, 36(6), 682-688.

Deren, S., Sanchez, J., Shedlin, M., Davis, W. R., Beardsley, M., Jarlais, D. D., et al.,(1996). HIV risk behaviors among Dominican brothel and street prostitutes in New York City. AIDS Education and Prevention, 8, 444-456.

Fingarette, H. (1988). Heavy drinking: The myth of alcoholism as a disease. Berkeley: University of California Press.

Fureman, B., Parikh, G., Bragg, A., \& McLellan, A. T. (1990). Addiction Severity Index ( $5^{\text {th }}$ ed.). Philadelphia, PA: The University of Pennsylvania/Veterans Administration Center for Studies of Addiction. Project Supported by National Institute on Drug Abuse and the Veterans Administration.

Gao, F., Bailes, E., Robertson, D. L., Chen, Y., Rodenburg, C. M., Michael, S. F., Cummins, L. B., Arthur, L. O., Peeters, M., Shaw, G. M., Sharp, P. M., \& Hahn, B. H. (1999). Origin of HIV-1 in the chimpanzee. Pan Troglodytes. Nature, 397(6718), 436-441. 
Genuis, S. J., \& Genuis, S. K. (2005). HIVIAIDS prevention in Uganda: Why has it worked? Postgraduate Medical journal, 81(960), 615-617.

Glaser, F. B., Heather, N., Drummond, D. C., Finney, J. W., Lindstrom. L., Sutton, S., Soyka, M., Stockwell, T., Hall, W., Godfrey, C., San, L., Gordis, E., Fuller, R., Negrete, J. C., \& Orford, J. (1999). Comments on project MATCH: Making alcohol treatment to client heterogeneity. Addiction, 94(1), 31-70.

Hansen, H., Lopez-Iftikhar, M. M., \& Alegria, M. (2002). The economy of risk and respect: accounts by Puerto Rican sex workers of HIV risk taking. Journal of Sex Research, 39, 292-301.

Harding, R., Dockrell, M. J. D., Dockrell, J., \& Corrigan, N. (2001). Motivational interviewing for HIV risk reduction among gay men in commercial and public sex settings. AIDS Care, 13(4), 493-501.

Hubbard, R. L., Marsden, M. E., Rachal, J. V., Harwood, H. J., Cavanaugh, E. R., Ivey, A. E., Gluckstern, N. B., \& Ivey, M. B. (1997). Basic influencing skills. $3^{\text {rd }}$ ed. North Amherst, MA: Microtraining Associates.

Joint United Nations Programme on HIVIAIDS (UNAIDS). (2004). Report on the global HIVIAIDS epidemic: 4th global report.

Kaiser Family Foundation. (2004). Women and HIVIAIDS in the United States (No. \#6092-02). Menlo Park, CA.

KAR (Kentucky Annual Report). Retrieved April 20, 2006 from http://www.Irc.state.ky.us/kar/902/002/020.htm 
Karon, J. M., Fleming, P. L., Steketee, R. W., \& De Cock, K. M. (2001). HIV in the United States at the turn of the century: An epidemic in transition. American Journal of Public Health 91(7), 1060-1068.

Keller, M. (1976). Problems with alcohol: an historical perspective. In Filstead, W., Rossi, J., and Keller, M. (Eds.). Alcohol and Alcohol Problems. Cambridge, MA: Ballinger Publishing Co.

Kentucky HIVIAIDS Semi-Annual Surveillance Report. (2004). Volume 2(2).

Kerr, D., \& Matlak, K. A. (1998). Alcohol use and sexual risk taking among adolescents: a review of recent literature. Journal of HIVIAIDS Prevention Education Adolescent Children, 2(2), 67-88.

Kilpatrick, D. G., Roitzsch, J. C., Best, C. L., McAlhany, D. A., Sturgis, E. T., \& Miller, W. C. (1978). Treatment goal preference and problem perception of chronic alcoholics: Behavior and personality correlates. Addictive Behaviors, 3, 107-116.

Koblin, B. A., Chesney, M. A., Husnik, M. J., Bozeman, S., Celum, C. L., Buchbinder, S., Mayer, K., McKiman, D., Judson, F. N., Yijian, H., \& Coates, T. J. (2003, June). High-risk behaviors among men who have sex with men in 6 US cities: Baseline data from the EXPLORE study American Journal of Public Health, 00900036, 93(6), 705-707.

KRS (Kentucky Revised Statutes). Retrieved April 20, 2006 from http://www.Irc.state.ky.us/kar/902/002/020.htm 
Lancaster, T. \& Stead, L. F. (2006). Review: self help interventions for smoking cessation are not effective unless tailored to the individual. EvidenceBased Medicine, 11(2), 48-48.

Littell, J. H., \& Girvin, H. (2002). Stages of change: A critique. Behavior Modification, 26(2), 223-274.

Logan, T., Cole, J., \& Leukefeld, C. (2003). Gender differences in the context of sex exchange among individuals with a history of crack use. AIDS Education and Prevention, 15(5), 448-464.

Marks, G., Crepaz, N., Senterfitt, J. W., \& Janssen, R. S. (2005). Meta-analysis of high-risk sexual behavior in persons aware and unaware they are infected with HIV in the United States. Journal of Acquired Immune Deficiency Syndromes. 39(4), 446-453.

Maxwell, M. A. (1950). The Washingtonian movement. Quarterly Journal of Studies on Alcoholism, 11, 410-451.

McClusker, J., Stoddard, A., Frost, R., \& Zorn, M. (1996). Planned versus actual duration of drug abuse treatment. Reconciling observational and experimental evidence. Journal of Nervous Mental Disorders, 184(8), 482489.

McLellan, A. T., Lubrosky, L., Cacciola, J., \& Griffith, J. E. (1985). New data from the Addiction Severity Index: Reliability and validity in three centers. The Journal of Nervous and Mental Disease, 173, 412-423.

Metzger, D. S., Navaline, H., \& Woody, G. E. (1998). Drug abuse treatment as HIV prevention. Public Health Reports, 133(Suppl. 1):97-106. 
Meyerhoff, D. J. (2001). Effects of alcohol and HIV infection on the central nervous system. Alcohol Research \& Health, 25(4), 288-298.

Milam, J. R., \& Ketcham, K. (1981). Under the influence: A guide to the myths and realities of alcoholism. Seattle, WA: Madrona Publications.

Miller, R. A. (2000). Enhancing motivation for change in substance abuse treatment. Treatment improvement protocols (TIPS) Series 35. DHHS Publication No. (SMA) 00-3460. Bethesda, MD: National Institute on Alcohol Abuse and Alcoholism.

Miller, W. R., \& Rollnick, S. (1991). Motivational interviewing: Preparing people to change addicted behavior. New York: Guilford Press.

Miller, W. R., \& Rollnick, S. (1998). Motivational interviewing: Professional Training Videotape Series. Retrieved May 2, 2006 from http://www.motivationalinterview.org/training/miorderform.pdf

Miller, W. R., \& Rollnick, S. (2002). Motivational interviewing: Preparing people to change addicted behavior. New York: Guilford Press.

Moos, R. H. (2003). Addictive disorders in context: principles and puzzles of effective treatment and recovery. Psychology of Addictive Behaviors, 17(1), 3-12.

National Household Survey on Drug Abuse. (2004).

National Institute on Alcohol Abuse and Alcoholism. (2001). Alcoholism: Getting the facts. (NIH Publication No. 96-4153). Bethesda, MD: U.S. Department of Health and Human Services. 
National survey results on drug use from the monitoring the future study. (19751994, 1996, 1997, 2000, \& 2001). Retrieved April 20, 2006 from http://monitoringthefuture.org/pubs.html\#monographs

Nir, Y., \& Cutler, R. (1978). The unmotivated patient syndrome: Survey of therapeutic interventions. American Journal of Psychiatry, 135, 442-447.

Norris, A. E., \& Ford, K. (1999). Sexual experiences and condom use of heterosexual, low-income African-American and Hispanic youth practicing relative monogamy, serial monogamy, and nonmonogamy. Sexually Transmitted Diseases, 26, 17-25.

Orford, J. (1985). Excessive appetites: A psychological view of addictions. New York: John Wiley and Sons.

Parsons, J. T. (2005). Motivating the unmotivated: A treatment model for barebackers. Journal of Gay \& Lesbian Psychotherapy, 9(3/4), 129-148.

Parsons, J. T., Rosof, E., Punzalan, J. C., \& DiMaria, L. (2005). Integration of motivational interviewing and cognitive behavioral therapy to improve HIV medication adherence and reduce substance use among HIV-positive men and women: results of a pilot project. AIDS Patient Care \& STDs, 19(1), 31-39.

Patterson, D. A., Cloud, R. N., \& McKiernan, P. M. (2004). Treating addicted HIV patients: The case for Motivational Interviewing. Counselor, 5, 33-39. Peele, S. (1985). The meaning of addiction. Lexington, MA: Lexington Books. Petry, N. (1999). Alcohol use in HIV patients: What we don't know may hurt us. International Journal of STD and AIDS, 10, 561-570. 
Prochaska, J. O., \& DiClemente, C. C. (1982). Transtheoretical therapy: Toward a more integrative model of change. Psychotherapy: Theory, Research and Practice, 19, 276-288.

Prochaska, J. O., \& DiClemente, C. C. (1984). The transtheoretical approach: Crossing the traditional boundaries of therapy. Malabar, FL: Krieger.

Prochaska, J. O., \& DiClemente, C.C. (1986). Toward a comprehensive model of change. In W. R. Miller \& N. Heather (Eds.), Treating addictive behaviors: Process of change. (pp.3-27). New York: Plenum.

Prochaska, J. O., \& Norcross, J. C. (2003). Systems of psychotherapy: A transtheoretical analysis, $5^{\text {th }}$ ed. Pacific Grove, CA: Brooks/Cole.

Prochaska, J. O., Norcross, J. C., \& DiClemente, C. C. (2002). Changing for good. New York, NY: Quill.

Project MATCH Research Group. (1993). Project MATCH: Rationale and methods for a multisite clinical trail matching patients to alcoholism treatment. Alcoholism: Clinical and Experimental Research, 17, 11301145.

Project MATCH Research Group. (1997). Project MATCH secondary a priori hypotheses. Addiction, 92, 1671-1698.

Project MATCH Research Group. (1997a). Matching alcoholism treatments to client heterogeneity: Project MATCH posttreatment drinking outcomes. Journal of Studies on Alcohol, 58, 7-29. 
Project MATCH Research Group. (1997b). Matching alcoholism treatments to client heterogeneity: Treatment main effects and matching effects on within-treatment drinking. Journal of Studies on Alcohol, 59, 631-639.

Rogers, C. R. (1951). Client-centered therapy. Boston: Houghton Mifflin.

Rogers, C. R. (1961). On becoming a person. Boston: Houghton Mifflin.

Rogers, C. R. (1980). A way of being. Boston: Houghton Mifflin.

Roozen, H. G., Van Beers, S. E., Weevers, H. J., Breteler, M. H., Willemsen, M. C., Postmus, P. E., \& Kerkhof, J. F. (2006). Effects on smoking cessation: Naltrexone combined with cognitive behavioral treatment based on the community reinforcement approach. Substance Use \& Misuse, 41(1), 4560 ,

Rounsaville, B. J., Carroll, K. M., \& Onken, L. S. (2001). A stage model of behavioral therapies research: getting started and moving on from stage 1. Clin Psychol Sci Prac, 8, 133-142.

Safren, S. A., Otto, M. W., Worth, J. L., Salomon, E., Johnson, W., Mayer, K., \& Boswell, S. (2001). Two strategies to increase adherence to HIV antiretroviral medication: Life-steps and medication monitoring. Behavior Research \& Therapy, 39(10), 1151-1163.

Selwyn, P. A., \& O'Connor, P. G. (1992). Diagnosis and treatment of substance users with HIV infection. Primary Care (Special issue: AIDS and HIV Infection in Office Practice), 19(1), 119-56.

Shilts, R., \& Grieder, W. (2000). And the band played on: Politics, people, and the AIDS epidemic. NY: St. Martins Press. 
Simpson, D. D. (1981). Treatment for drug abuse. Follow-up outcomes and length of time spent. Archives of General Psychiatry, 38, 875-880.

Sorensen, J. L., Masson, C. L., Delucchi, K., Sporer, K., Barnett, P.G., Mitsuishi, F., Lin, C., Yong, S., TeChieh, C., \& Hall, S. H. (2005). Randomized trial of drug abuse treatment-linked strategies. Journal of Consulting \& Clinical Psychology, 73(6), 1026-1035.

Steiner, C. (1971). Games alcoholics play. New York: Grove Press.

Substance Abuse and Mental Health Services Administration. (2004). Results from the 2003 National Survey on Drug Use and Health: National Findings (Office of Applied Studies, NSDUH Series H-25, DHHS Publication No. SMA 04-3964). Rockville, MD.

Surratt, H. L., Inciardi, J., Kurtz, S., \& Kiley, M. (2004). Sex work and drug use in a subculture of violence. Crime and Delinquency, 50(1), 43-59.

Taleff, M. J. (1997). A handbook to assess and treat resistance in chemical dependency. Dubuque, IA: Kendall/Hunt.

The living Bible. Proverbs 23.

Treisman, G. J., \& Angelino, A. F. (2004). The psychiatry of AIDS: A guide to diagnosis and treatment. Baltimore Maryland: The John Hopkins University Press.

Trice, H. M. (1958). Alcoholics Anonymous. Annals of the American Academy of Politics and Social Sciences, 315, 108-116.

Tucker, J., Burnam, M. A., Sherbourne, C. D., Kung, F., \& Gifford, A. L. (2003, May). Substance use and mental health correlates of nonadherence to 
antiretroviral medications in a sample of patients with human immunodeficiency virus infection. American Journal of Medicine, 114(7), 573.

UNAIDS. (2004). Retrieved April 20, 2006 from http://www.unaids.org/bangkok2004/GAR2004 html/GAR2004 00 en.htm

U.S. Census Bureau. (2004). Retrieved April 20, 2006 from U.S. Census Bureau *http://quickfacts.census.gov/qfd/states/00000.html

Walizter, K. S., Dermen, K. H., \& Connors, G. J. (1999). Strategies for preparing clients for treatment - A review. Behavior Modification, 23, 129-151.

Windle, M. (1997). The trading of sex for money or drugs, sexually transmitted diseases (STDs), and HIV-related risk behaviors among multisubstance using alcoholic inpatients. Drug and Alcohol Dependence, 49(1):33-38.

Zaidi, I. F., Crepaz, N., Song, R., Wan, C. K., Lin, L. S., Hu, D. J., and Sy, F. S. (2005). Epidemiology of HIVIAIDS among Asians and Pacific Islanders in the United States. AIDS Education \& Prevention, 17(5), 405-417.

Zhu, T., Korber, B. T., Nahmias, A. J., Hooper, E., Sharp, P. M., \& Ho, D. D. (1998). An African HIV-1 sequence from 1959 and implications for the origin of the epidemic. Nature 5, 391, 594-597.

Zweben, A., \& Zuckoff, A. (2002). Motivational Interviewing and treatment adherence. In W.R. Miller \& S. Rollnick (Eds.) Motivational Interviewing: Preparing people to change (2 $\left.2^{\text {nd }} e d\right)$, (pp 299-319) New York: Guilford. 


\section{APPENDIX A \\ Description of Volunteers of America of KY Intensive Outpatient Alcohol/Drug Treatment}




\section{Description of Volunteers of America of KY Intensive Outpatient Alcohol/Drug Treatment}

Program Description: The Outpatient Clinic has been designed to offer Gender Specific Programming for both men and women who are HIV positive, and/or at high risk for HIV and alcohol/drug dependent. The program is to provide persons, who are HIV and alcoholic/drug dependent, treatment and case management services. There are two separate Intensive Outpatient tracks: one for women and one for men the women meet from 9:00 am - 1:00 pm, and the men meet from 1:00-5:00 pm, Monday through Friday. We offer childcare for both women and men who have children while they are in treatment.

Admission Criteria: Eighteen years or older who are alcohol/drug dependent with HIV and/or at high risk for HIV.

Services Offered: The services provided are gender specific 90 minute group counseling sessions, Recovery Dynamics, life skills, vocational and career development, parenting classes, health issues, domestic violence counseling, intensive case management/outreach services and continuing care services. The program also has the capability to provide psychiatric consult and evaluation. We also provide childcare services and referrals for child enrichment programs. Contact Person(s) Lynda Durrett, Program Manager or Deb Reinhardt, Director of Women's Outpatient \& Alcohol Drug Programs office: (502)635-4513 fax: (502) 636-0597. 


\begin{abstract}
APPENDIX B
Human Subjects Protection Program Office's Institutional Review Board (IRB) Amendment to Reflect the Addition of Up to Five Additional Motivational Interviewing Sessions
\end{abstract}




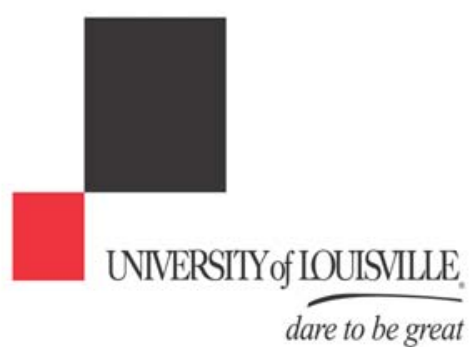

dare to be great

STUDY TITLE: Technical assistance and program evaluation (longitudinal followup study) of the Volunteers of America targeted expansion initiative for substance abuse and HIV prevention in minority communities. (CSAT \# TI-14491 \& TI-15852)

\section{Subject Informed Consent}

Introduction and Background Information: You are invited to participate in a research study.

The study is being conducted by Richard N. Cloud, Ph.D. and Linda K. Bledsoe, Ph. D. The study is sponsored by the University of Louisville Kent School of Social Work and a grant from the federal department of Health and Human Services, Substance Abuse and Mental Health Services Administration, Center for Substance Abuse Treatment (CSAT) that was awarded to Volunteers of America (VOA). Money from the grant is being paid to the University of Louisville, Kent School of Social Work to conduct this study. The study involves your involvement in two interviews that will take place at the VOA or some other agreeable site. Approximately 200 subjects will be invited to participate. Your participation in this study will last for one year following treatment.

Purpose: The purpose of this research study is to test effectiveness of the VOA treatment program at reducing substance abuse and to reduce practices known to spread HIVIAIDS. Your involvement in the study will consist of two interviews expected to last about one hour each. These two interviews will be conducted at approximately six and twelve months following the date that you started treatment at VOA.

Procedures: At these two interviews, you will be asked to complete many (but not all) of the questionnaires that you completed when you signed up for the VOA treatment program. One questionnaire includes several questions related to how your life is going in general, substance abuse, and practices known to spread HIVIAIDS. In addition, we will be asking you to complete four questionnaires that provide information on conditions that are known to reduce substance abuse, including: AA and NA involvement; motivation to stay clean and sober; support from friends; and temptation to use drugs and alcohol. In general, we will compare responses of subjects at the time treatment began to responses to the same questions six and twelve months later. You may refuse to answer any question that makes you uncomfortable.

Additionally, some people may be asked to participate in one to five more motivational counseling sessions in order to see if it increases your retention in treatment services. If you agree to participate in these additional interviews, please complete the checkboxes below:

You agree to participate in the additional counseling sessions Initial Here 
Potential Risks: There is a risk that participating in the study could lead to a breach in confidentiality. This means people could learn of your participation in the study. Since the program is treating substance abuse among those who have HIV and those at risk of contracting HIV, this information could result in some form of discrimination. For this reason, it is critical that you are careful to maintain absolute confidentiality of the other participants in treatment. We are taking several steps to safeguard confidentiality of participants. In addition, some of the questions on illicit drug use and sexual practices could be incriminating. Because of this we have sought legal protection to reduce a highly unlikely risk that a court might subpoena these records (see Certificate of Confidentiality below). In addition, there may be unforeseen risks that cannot be anticipated.

Certificate of Confidentiality: To help us protect your privacy, we have obtained a Certificate of Confidentiality from the federal government. With this Certificate, the investigators cannot be forced (for example by court subpoena) to disclose your name or other information that may identify you in any federal, state, or local civil, criminal, administrative, legislative, or other proceedings. The Department of Health and Human Services (DHHS) may see your information (only for audit or program evaluation), and we may voluntarily disclose information if we think harm to yourself or others, including child abuse, is probable. None of this implies DHHS approval or disapproval. If an insurer, employer, or other person obtains your written consent to receive research information, then the researchers may not use the Certificate to withhold that information. The Certificate of Confidentiality does not prevent the researchers from disclosing voluntarily, without your consent, information that would identify you as a participant in the research project under the following circumstances: if we should become aware of any act of child abuse, or any intent to harm yourself or another person during the course of the interview.

Confidentiality: Although absolute confidentiality cannot be guaranteed, we are taking steps and are committed to protecting your privacy. The study sponsor, the Institutional Review Board (IRB), the Human Subjects Protection Program Office (HSPPO), personnel conducting the research including those from the Kent School of Social Work may have access to research records. Should the data collected in this research study be published, your identity will not be revealed.

Benefits: The possible benefits of this study include helping VOA to do the research that they agreed to do in their agreement with CSAT, which in turn, will help to insure that VOA continues to receive money to pay for future substance abuse treatment services benefiting both you and others. In addition, while the information collected may not benefit you directly, what is learned may benefit VOA and American society by leading to improved methods to treat substance abuse and to reduce the spread of HIV. Compensation: You will receive $\$ 20$ for completing the six-month and the twelve-month interviews ( $\$ 20$ for each interview or $\$ 40$ for both interviews). Those agreeing to participate in the additional counseling will not be paid extra.

Voluntary Participation: Your participation in this research study is voluntary. You may refuse to participate and you are free to withdraw your consent at any time without penalty or losing benefit to which you are otherwise entitled. 
Research Subject's Rights and Contact Persons: You acknowledge that all your present questions have been answered in language you can understand and all future questions will be treated in the same manner. If you have any questions about the study, please contact Richard N. Cloud, Ph.D. at 502-299-1385.

If you have any questions about your rights as a research subject, concerns or complaints about the research or research staff, you may call the HSPPO at 502-8525188. You will be given the opportunity to discuss any questions about your rights as a research subject, in confidence, with a member of the IRB. The IRB is an independent committee composed of members of the University community, staff of the institutions, as well as lay members of the community not connected with these institutions. The IRB has reviewed this study.

Consent: You have discussed the above information and hereby consent to voluntarily participate in this study. You will be given a signed copy of the consent.

Signature of Subject

Date Signed

Person Explaining the Consent

$\overline{\text { Date Signed }}$

Signature of Investigator

Date Signed 


\section{APPENDIX C \\ Motivational Interviewing \\ Protocol for Sessions on Retention}




\section{Motivational Interviewing}

Protocol for Sessions on Retention

\begin{tabular}{|l|l|}
\hline \multicolumn{1}{|c|}{ Sources of Non-Adherence } & \multicolumn{1}{|c|}{ Motivational Strategies } \\
\hline $\begin{array}{l}\text { Uncertainly or ambivalence } \\
\text { about change }\end{array}$ & Persistent empathy and non-defensiveness \\
\hline $\begin{array}{l}\text { Concerns about the suitability } \\
\text { of the treatment modality } \\
\text { offered }\end{array}$ & Normalizing gradual development of trust \\
\hline $\begin{array}{l}\text { Misperceptions about treatment } \\
\text { needs }\end{array}$ & $\begin{array}{l}\text { Exploring understanding of how treatment } \\
\text { works }\end{array}$ \\
\hline $\begin{array}{l}\text { Previous negative treatment } \\
\text { experiences }\end{array}$ & Eliciting perceptions of treatment needs \\
\hline $\begin{array}{l}\text { Negative general relationship } \\
\text { expectancies }\end{array}$ & Decisional balancing \\
\hline Culture-specific differences & Reviewing past treatment experiences \\
\hline Stigma & $\begin{array}{l}\text { Exploring and addressing previous and future } \\
\text { barriers to change in treatment }\end{array}$ \\
\hline Mandated treatment/coercion & Negotiating proximal goals \\
\hline $\begin{array}{l}\text { High barriers to care (financial } \\
\text { problems, family hardships) }\end{array}$ & Communicating a non-perfectionist message \\
\hline $\begin{array}{l}\text { Low self-efficacy in handling } \\
\text { treatment demands }\end{array}$ & $\begin{array}{l}\text { Recognizing non-adherence as a sign of } \\
\text { damaged rapport }\end{array}$ \\
\cline { 2 - 2 } & Addressing breeches in rapport \\
\cline { 2 - 2 } & $\begin{array}{l}\text { Involving a supportive other for motivational } \\
\text { support }\end{array}$ \\
\cline { 2 - 2 } & $\begin{array}{l}\text { Identifying positive experiences of receiving } \\
\text { help }\end{array}$ \\
\cline { 2 - 2 } & Supporting self-efficacy or coping capacities \\
\cline { 2 - 2 } & $\begin{array}{l}\text { Displaying optimism about treatment } \\
\text { effectiveness }\end{array}$ \\
\hline
\end{tabular}




\section{CURRICULUM VITA \\ DAVID A. PATTERSON \\ Silver Wolf (Adelv unegv Waya) \\ 2955 Brownsboro Road \\ Louisville, KY 40206 \\ (502) 819-2255 Cell \\ (502) 895-5487 Home \\ davidpatt@insightbb.com \\ EDUCATIONAL EXPERIENCE}

University of Louisville/University of Kentucky

Kent School of Social Work Ph.D. Program

5/2003 to Present (Defense 4.20.2006)

University of Louisville, Kent School of Social Work

8/1996 to $12 / 1997$

Degree: Masters of Science in Social Work (MSSW)

Spalding University

1/1994 to 5/1996

Degree: Bachelors of Science in Social Work (BSW)

Jefferson Community College

$1 / 1992$ to $12 / 1993$

\section{CERTIFICATIONS}

Certified Alcohol and Drug Counselor (CADC) since 12/1996 Certified Social Worker (CSW) 1998 to 2003

Recovery Dynamics Trainer since 5/1992

HIVIAIDS Pre \& Post- Test Counseling since 6/1994

\section{WORK EXPERIENCE}

University of Louisville

Co-Investigator/Research Coordinator 7/05 to Present

See details below under "Contracts and Grants"

Volunteers of America of Kentucky and Tennessee 
Manager -- Outreach \& Motivational Counseling Services 11/03 to 7/05 (Funded by Center for Substance Abuse Treatment, CSAT) Manage newly funded five-year program (\$398,195 yearly) designed to offer outreach services and Motivational Interviewing sessions in order to address treatment retention issues.

Responsible for the overall management of three programs and services (total budget approx. \$1 million yearly) 9/02 to 11/03:

\section{Intensive Outpatient Programs Services Manager}

(Funded by Center for Substance Abuse Treatment, CSAT) Manage Intensive Outpatient Program which provides alcohol and drug treatment services for individuals needing those specific services, and whom are considered high-risk for HIVIAIDS or currently HIVIAIDS positive.

\section{STOP HIV-Out-Reach Manager}

(Funded by Center for Disease Control and Prevention, CDC) Manage STOP Out-Reach staff consisting of six out-reach prevention specialists and two prevention case managers who provide services to men having sex with men, gay men of color, high risk minority heterosexuals and intravenous drug users.

\section{HOPWA Manager}

(Funded by Housing and Urban Development, HUD) Management of Housing Opportunity for Persons With AIDS (HOPWA) consisting of providing rental, clothing, alcohol and drug services, food \& travel vouchers, as well as other human services related assistance for HIV-infected individuals.

\section{Patterson \& Associates (P\&A)}

Owner 2/2002 to Present

Provides individual, couple, family counseling; employee assistance programs \& work life services; along with training \& educational workshops.

Wood-IN, LLC

General Manager 3/1999 to 9/2002

Responsible for all aspects of family-owned wood manufacturing operations (average $\$ 175,000$ monthly sales).

\section{Volunteers of America of KY}

HIV Out-Reach Manager \& Third Step Program Manager 3/1998 to 3/1999

Managed two programs, the Third Step Program is a long-term alcohol and drug treatment facility that provides assessments, individual and group therapy, recovery related lectures, and family therapy. The HIV Out-Reach Program focuses on working in the community (jails, shelters, hospitals, \& social services agencies) to identify the target population of the grant, i.e. sero-positive persons with alcohol and drug problems. 
Jefferson County Attorney's Office

Adult \& Juvenile Drug Court Diversion Program

Program Leader 7/1996 to 3/1998

Designed and implemented program policies and procedures, coordinated community resources, developed program curriculum, supervised counselors and out-reach workers.

\section{Volunteers of America of Kentucky's Third Step Program \\ Counselor II 12/1994 to 7/1996 \\ Counselor I 8/1993 to $12 / 1994$ \\ Resident Manager 6/1991 to 8/1993}

Provided assessments, case management, individual \& group therapy, prepared and delivered recovery lectures, developed individual treatment plans, and referrals for community-based services.

\section{PAST \& PRESENT MEMBERSHIPS}

University of Louisville's Human Protection Committee's International Review Board (IRB) Social \& Behavioral Committee Member, current Applied Research Ethics National Association Member (ARENA), current National Association of Alcohol and Drug Addiction Counselors (NAADAC) Member since1996

National Association of Social Workers (NASW) Member 1996 to 2003 AIDS Service Center Coalition (ASCC) Board Member, current People Advocating Recovery (PAR) Member, current The Cherokee Tribe of Kentucky, current Smithsonian's National Museum of the American Indian (NMAl) Sky Meadows Circle Charter Member, current Cherokee National Historical Society Member, current National Trail of Tears Association Member, current President, Kentucky Association of Addiction Professionals (KAAP) Louisville Chapter - Served two year term 1996 to 1998

President-Elect, Kentucky Association of Addiction Professionals (KAAP) Louisville Chapter - Served two year term 1994 to 1996

Editor, KAAPsule News Letter - Served two year term 1995 to 1997

\section{AWARDS \& TRAINING FELLOWSHIPS}

National Institute of Health's (NIH) Ruth L. Kirschstein National Research Service Award Minority Predoctoral Fellowship Program. A Predoctoral fellowship funding my dissertation research on the effects of a motivational intervention on treatment retention and completion issues for HIV-infected alcoholics receiving intensive outpatient services (Scored twice).

2005 June, Center for Disease Control/Association for Schools of Public Health, Institute for HIV Prevention Leadership Training: Adapting and 
Tailoring Evidence-Based Interventions. Three day all expense paid training in Atlanta Georgia.

2005 PRICE Fellowship. A fellowship in Atlanta, Georgia at the Center for Disease Control and Prevention (CDC) facility. The Price Fellowships program offers the opportunity to three individuals from community-based and/or nongovernmental organizations (CBO/NGOs), committed to preventing HIV infection, to work closely for one month with health professionals at CDC. (National finalist).

2004 Center for Disease Control/Association for Schools of Public Health, Institute for HIV Prevention Leadership. A comprehensive, capacity building educational program offered over a period of nine months and includes four weeks of on-going instructions provided once every quarter in Atlanta, GA.

2004 PRICE Fellowship Reviewer. Reviewed applications for the Center For Disease Control and Prevention's (CDC) 2004 Price Fellowships for HIV Prevention.

Research Assistantship. Awarded full tuition reimbursement while obtaining a Ph.D.

Spalding University Irish Initiative Scholarship. Received funds to travel and study and research social services in Cork, Ireland during the month of March 1996.

Spalding University Leadership Scholarship 1994. Awarded tuition reimbursement while obtaining a BSW.

Volunteers of America's 1992 Volunteer Of The Year. Provided over 2000 hours of volunteer services in 1991 within alcohol and drug programs.

\section{PUBLICATIONS IN PEER REVIEWED JOURNALS}

Cloud, R. N., Besel, K., Bledsoe, L., Golder, S., McKiernan, P., Patterson, D. A., \& Ziegler, C. (Forthcoming). Using brief Motivational Interviewing techniques to increase post treatment twelve-step meeting attendance: Opportunities and challenges. Alcoholism Treatment Quarterly, 24(3).

Patterson, D. A., Cloud, R. N., \& McKiernan, P. M. (2004). Treating addicted HIV patients: The case for Motivational Interviewing. Counselor, 5, 33-39.

\section{ARTICLE UNDER REVISE and RESUBMIT}

Patterson, D. A. Analyzing HIVIAIDS and Addiction as a Social Problem. Journal of Psychology \& Human Sexuality. 


\section{RESEARCH \& DATA ANALYSIS UNDERWAY}

Barve, S., \& Patterson, D. A. Analysis of data from India (n=approximately 1300) of those who are HIV-infected, positive for TB, alcoholics and non-alcoholic, along with other medical data related to health issues in that country.

Cloud, R. N., McKiernan, P. M., \& Patterson, D. A. Title: Developing a protocol of how social work colleges can assist substance abuse agencies in improving practice: A pilot study sponsored by the Volunteers of America of KY and TN. A pretest posttest experimental design exploring whether student involvement using the most basic motivational interviewing spirit affects program retention and after care compliance within three alcohol and drug residential programs for men.

Cloud, R. N., McKiernan, P. M., Patterson, D. A., \& Cooper, L. Effects of substance abuse treatment on patients who are HIV-infected or at a heightened risk for HIV. The first year cohort (n=approximately 130) has been followed up on several outcomes (e.g. substance use, sexual practices, self efficacy over AoD use, motivation to change, enhanced friendship, networks, involvement in 12step programs) at baseline and six months post-intake. Initial data analysis has been initiated on this follow-up interval. These subjects will also be followed up at the one-year post intake. This is a five-year evaluation of treatment study sponsored by SAMHSA and Volunteers of America of KY and TN.

Cooper, L., Cloud, R. N., Hill, J., McKiernan, P., \& Patterson, D. A. Results of a focus group of HIV-infected clients describing reasons that may contribute to substance abuse treatment dropout. Research sponsored by SAMHSA and Volunteers of America of Kentucky and Tennessee.

Besel, K., Cloud, R.N., Hill, J., McKiernan, P., Cooper, L., \& Patterson, D.A. Analysis of qualitative interviews describing barriers to initiation of substance abuse treatment among HIV-infected clients.

TEACHING

Fall, 2005: Adjunct Professor, University of Louisville's Kent School of Social Work.

SW 668 Advanced Research Practice I (Core Course). Three credit hours

Summer, 2005: Adjunct Professor, University of Louisville's Kent School of Social Work.

SW 697 Motivational Interviewing (Elective Course). Three credit hours

Spring, 2005: Adjunct Professor, Spalding University School of Social Work Louisville KY. 
SW 420 Chemical Dependency (Core Course). One credit hour. SW 616 Addiction in Society (Core Course). One credit hour.

Fall, 2004: Co-Teaching. University of Louisville's Kent School of Social Work. SW 697 Motivational Interviewing (Elective Class). Mentor: Richard N. Cloud, MSW, Ph.D.

Spring, 2004: Teaching Practicum. University of Louisville's Kent School of Social Work. SW 605 Foundation Generalist Practice II (Core Course). Mentor: Seana Golder, MSW, Ph.D.

\section{TRAININGS \& INVITED PRESENTATIONS}

Alcohol and Drug Diagnosis Presentation: Spring 2005 (2 hour presentation), MSSW Course Psychopathology, Dr. Stanley Frager, Kent School of Social Work.

HIV \& Addiction: Healing the Brain and the Body: 2004 African American and Hispanic Leadership Conference on HIVIAIDS. September 2004

The Addicted HIV-Infected Individual: 2003 African American and Hispanic Leadership Conference on HIVIAIDS. September 2003.

Neurotherapy: Understanding the Brain's Impact on Treating Alcoholism. University of Louisville Kent School of Social Work's Spring Conference 2003.

Basic Alcohol and Drug Information. Kentucky Cabinet for Family \& Children. January 1999.

\section{Volunteers of America of Kentucky \& Tennessee Training Institute}

Basic Counseling Theories. April 2004.

Professional Interventions that Facilitate 12-Step Involvement. January 2004.

Basic, Intermediate, and Advanced Group Counseling. February 2003.

Special Populations in Treatment: HIV, Women, \& Criminal Justice Clients. November 2003.

Neurotherapy. November 2002.

\section{Recovery Dynamics Trainings}

Volunteers of America's Third Step Program. 1992

Volunteers of America's Freedom House 1993

Volunteers of America's Hope House 1994

Indiana Department of Correction's Branchville Prison 1994

Paducah KY's Alcohol and Drug Treatment Clinic 1994

Jefferson County Medical Society 1995

Louisville KY's Charter Hospital 1995 
Jefferson Alcohol and Drug Abuse Clinic 1996

Kentucky Drug Court Programs 1997

\section{CONTRACTS \& GRANTS}

NIH-NIAAA grant application: Mechanisms of Alcohol-Induced ImmunoSuppression (R01 AA014371-01A1) Test the effects of ethanol on PBMCs/CD4+T-cells obtained from alcoholic patients and abstinent, healthy control subjects. The efficacy of exogenous SAMe supplementation in attenuating CD4+T-cell death induced by alcohol will also be determined. (Five year award, University of Louisville School of Medicine, Sept. 2004 to June 2009) Role: Sub-Investigator.

NIH-NIAAA grant application: Improving posttreatment Alcoholics Anonymous utilization in response to (1 R03 AA14578-01A1; $\$ 73,000$ for two years, including indirect, or $\$ 146,000$ total). Testing an intervention consisting of two components, a brief motivational session combined with a recovery mentor, to improve posttreatment involvement in twelve step programs. (Two year award, University of Louisville School of Social Work, May 2004 to Apr 2006) Role: CoInvestigatorl Research Coordinator.

Substance Abuse and Mental Health Services Administration-Center for Substance Abuse Treatment contract with Volunteers of America of Kentucky (CSAT \#TI-14491-01; Grantee Project Name: Gender Specific Intensive Outpatient Program for HIV; $\$ 79,920$ per year renewable for five years beginning $10 / 1 / 2002 ; \$ 399,600$ total, plus $\$ 8,150$ supplement during the first year totaling $\$ 407,750)$. Goal: Addiction treatment for those who are HIV positive or at high risk. Role: Co-Investigatorl Research Coordinator.

Substance Abuse and Mental Health Services Administration-Center for Substance Abuse, Center for Substance Abuse Treatment contract with Volunteers of America (CSAT \#TI 03-008; $\$ 68,000$ for five years or $\$ 340,000$ total; $12.5 \%$ FTE; first year award began 10/1/2003). Goal of grant: Addiction treatment outreach to people who are HIV positive. Role: Co-Investigatorl

\section{Research Coordinator.}

Kentucky Cabinet for Health Services (CHS), Department for Public Health's (DPH) cooperative agreement funds from the Center for Disease Control and Prevention (CDC) focusing on HIV prevention. Responded to a Request For Proposal while at the Volunteers of America and awarded $\$ 41,500$ for one Prevention Specialist and supplies targeting Minority/High Risk Heterosexuals. (One year contract, Volunteers of America of KY \& TN, starting August 2003 Document \#S-03261411). Role: Grant writer, Manager.

Kentucky Housing and Urban Development's (HUD) Housing Opportunities for Persons With AIDS (HOPWA). Responded to a multi-site Request For Proposal 
while at the Volunteers of America and awarded approximately $\$ 300,000$ for rental assistance and other services specifically for HIV-infected persons. (Three year contract, Volunteers of America of KY \& TN, starting February 2004). Role:

\section{Grant writer.}

Kentucky Cabinet for Health Services (CHS), Department for Public Health's (DPH) cooperative agreement funds from the Center for Disease Control and Prevention (CDC) focusing on HIV prevention. Responded to a Request For Proposal while at the Volunteers of America and awarded \$714,400 for eight Prevention Specialists and supplies targeting Men who have Sex with Men (MSM), Intravenous Drug Users (UDI), Minority/High Risk Heterosexuals (HRH), and Two HIV+ Prevention Case Managers. (Two year contract, Volunteers of America of KY \& TN, starting April 2004 Document \#S-0343912). Role: Grant writer. 